\title{
INTERACTIONS BETWEEN FAMILY AND SCHOOL ENVIRONMENTS: EVIDENCE ON DYNAMIC COMPLEMENTARITIES?
}

\author{
Ofer Malamud \\ Cristian Pop-Eleches \\ Miguel Urquiola \\ Working Paper 22112 \\ http://www.nber.org/papers/w22112 \\ NATIONAL BUREAU OF ECONOMIC RESEARCH \\ 1050 Massachusetts Avenue \\ Cambridge, MA 02138 \\ March 2016
}

For useful feedback we are thankful to Douglas Almond, Miikka Rokkanen, and seminar participants at Calgary, the NBER, the New York Fed, NYU, Rensselaer, Santa Barbara, TelAviv, UI Chicago, and UT Austin. For financial support, we are grateful to the National Science Foundation (SES 0819776), and to Columbia's Institute for Social and Economic Research and Policy (ISERP) and Program for Economic Research (PER). The views expressed herein are those of the authors and do not necessarily reflect the views of the National Bureau of Economic Research.

NBER working papers are circulated for discussion and comment purposes. They have not been peer-reviewed or been subject to the review by the NBER Board of Directors that accompanies official NBER publications.

(C) 2016 by Ofer Malamud, Cristian Pop-Eleches, and Miguel Urquiola. All rights reserved. Short sections of text, not to exceed two paragraphs, may be quoted without explicit permission provided that full credit, including ( $)$ notice, is given to the source. 
Interactions Between Family and School Environments: Evidence on Dynamic Complementarities? Ofer Malamud, Cristian Pop-Eleches, and Miguel Urquiola

NBER Working Paper No. 22112

March 2016

JEL No. I00

\begin{abstract}
$\underline{\text { ABSTRACT }}$
This paper explores whether conditions during early childhood affect the productivity of later human capital investments. We use Romanian administrative data to ask if the benefit of access to better schools is larger for children who experienced better family environments because their parents had access to abortion. We combine regression discontinuity and differences-indifferences designs to estimate impacts on a high-stakes school-leaving exam. Although we find that access to abortion and access to better schools each have positive impacts, we do not find evidence of significant interactions between these shocks. While these results suggest the absence of dynamic complementarities in human capital formation, survey data suggest that they may also reflect behavioral responses by students and parents.

Ofer Malamud

Harris School of Public Policy Studies

University of Chicago

1155 East 60th Street

Chicago, IL 60637

and NBER

malamud@uchicago.edu

Cristian Pop-Eleches

The School of International and Public Affairs

Columbia University

1401A International Affairs Building, MC 3308

420 West 118th Street

New York, NY 10027

and NBER

cp2124@columbia.edu

Miguel Urquiola

Columbia University

SIPA and Economics Department

1022 IAB, MC 3308

420 West 118th Street

New York, NY 10027

and NBER

msu2101@columbia.edu
\end{abstract}




\section{INTRODUCTION}

There is clear evidence that family and school environments can each have causal impacts on individuals' outcomes. In the family dimension, for example, Black, Devereux, and Salvanes (2007) and Royer (2009) show that individuals' schooling levels depend on their birthweight, and Doyle (2007) shows that earnings vary with foster care placement. In the school dimension, Chetty et al. (2011) find impacts of kindergarten quality on earnings, and Deming et al. (2014) of school quality on postsecondary attainment.

Much less is known about how family and school environments interact in determining outcomes. This is of particular interest given that dynamic complementarities may characterize these interactions. Specifically, Cunha and Heckman (2007) suggest that human capital investments may be more productive when an individual's baseline stock of skills is higher. Such complementarities are highly policy-relevant. The greater their magnitude, for instance, the stronger the argument that early family-related interventions may promote equity even as they raise the effectiveness of subsequent investments in school quality.

This paper uses Romanian data to make two contributions regarding the estimation of dynamic complementarities. First, we address the substantial empirical challenge summarized by Almond and Mazumder (2013): "causal inference on dynamic complementarities requires (a) exogenous variation in the baseline stock and (b) exogenous variation in subsequent investment ... In an observational setting, this may be asking for lightning to strike twice: two identification strategies affecting the same cohort but at adjacent developmental stages." We attempt to identify two such "lightning strikes" by combining variation on how the lifting of an abortion ban affects children's family environments, with variation on how the allocation of high school slots affects their school environments. We use administrative data to show that access to a higher quality environment in each of these dimensions improves individuals' outcomes, but find little indication of interactions between these impacts.

Our second contribution is to provide direct evidence that reduced form estimates exploiting two "lightning strikes" may be necessary but not sufficient to isolate complementarities in the sense of Cunha and Heckman (2007). We point out that even if there are dynamic complementarities in the technology of human capital formation - even if, all else equal, skill begets skill - these may be reinforced or undone if parents or teachers respond endogenously to children's prior achievement. For example, dynamic complementarities may be mitigated if children who initially attain high levels of skill receive lower parental or teacher attention later on. We explore this possibility using data from a survey we administered to a subset of families in the administrative data. We find suggestive evidence that parents and children behave in ways that would tend to undo dynamic complementarities. We therefore conclude 
that our reduced form results are not necessarily inconsistent with the existence of dynamic complementarities.

More specifically, our first source of variation comes from the repeal of Romania's decadeslong ban on abortions. This occurred on December 26, 1989, immediately after the collapse of Communism. We evaluate the impact of this change by comparing children born before and after July 1, 1990. July is the first month during which a decline in the number of births is observed, consistent with expectant mothers in their first trimester first having been able to access abortion six months earlier. ${ }^{1}$ The parents of children born after July 1 were thus potentially better able to plan for their arrival, and hence to provide them with good family environments and early parental investments. The pre and post-reform cohorts transitioned from middle to high school in 2005 and 2006. We use administrative data to observe their performance on a transition score used to determine admission to high school, and on a Baccalaureate exam taken at the end of high school (in 2009 and 2010). Both of these are high stakes outcomes, and the latter significantly influences admissions to college. We use a difference-in-differences (DD) estimation strategy to show that children born when there was greater access to abortion display higher achievement in both exams.

The second source of variation comes from the way children are allocated to high schools in Romania. Their ability to choose a school depends solely on the transition score, which includes performance on a standardized high school admissions exam. After obtaining their transition score, students request schools and are allocated via a centralized process that honors higher scoring students' requests subject to slot constraints. This gives rise to cutoff scores that determine access into schools, with clear discontinuities in educational quality, as measured by peer ability, at these thresholds. We use these cutoffs in a regression discontinuity (RD) design to show that students who have access to better high schools perform better on the Baccalaureate exam. ${ }^{2}$

We then combine the two sources of variation using a regression discontinuity differencein-differences (RD-DD) design. This allows us to test whether children who were born when there was greater access to abortion experience larger Baccalaureate score improvements when they have access to a better high school. In other words, we ask if the later intervention - better high school quality - produces greater gains among students who had higher initial stocks of skill due to being born after access to abortion increased. We do

\footnotetext{
${ }^{1}$ As in other countries, medical practice in Romania restricted abortions to the first trimester of pregnancy.

${ }^{2}$ We will henceforth refer to higher-ranked schools as better schools, although we acknowledge that this is only as measured by average transition scores. Pop-Eleches and Urquiola (2013) show that this measure is correlated, in the expected directions, with factors like parental involvement, teacher seniority, and perceptions of quality on the part of parents and school principals. We also note that our results on access to better schools replicate those in Pop-Eleches and Urquiola (2013), although for a different set of cohorts.
} 
not find significant evidence of this; if anything, there is indication of a negative interaction between the impact of better family and school environments.

We then consider behavioral responses using a survey administered to approximately 6,800 students and parents drawn from the administrative data. We focus this exercise on parental and student effort around homework. Although using survey rather than administrative data reduces statistical power, we find suggestive evidence that children who attend better schools receive less parental help with homework. Further, this effect is more pronounced for those who, due to the increased access to abortion, attained higher levels of skill early on. There is a similar pattern in terms of children's own effort. These responses suggest that, at least in the Romanian setting, parental and student behavior may tend to undo dynamic complementarities in human capital formation. To summarize, well-identified evidence is necessary to make progress on dynamic complementarities, but as often, reduced form results do not necessarily reveal the possibly countervailing mechanisms that underlie them.

Finally, we address three sets of issues that emerge in the context of our setup. First, the effects we find might be driven by changes in crowding, since significantly smaller cohorts were born in the months after access to abortion increased. For instance, these children might have encountered less competition for primary school slots. This issue is mitigated in our setting because, due to the timing of the collapse of communism, the children born just before and just after the decline in fertility entered school in the same academic year. Thus, they were likely to have encountered similar crowding conditions in schools.

Second, the increased access to abortion might have affected not just the investments that certain cohorts received, but also the composition of children in these cohorts. For example, it could have increased the prevalence of children of lower socioeconomic status. In the extreme, if composition were the only source of changes in the levels of skill induced by increased access to abortion, our results would reveal the heterogeneous effects of school quality by parental characteristics, rather than dynamic complementarities per se. We present evidence that composition, at least in terms of observables, does not drive our findings. We find only limited evidence that access to abortion affected mothers' characteristics. In addition, our key results continue to hold when we control for measures of poverty in the administrative data, and for characteristics such as mother's education in the survey data.

Third, the children born before and after access to abortion increased may be differentially distributed across the cutoffs that determine access to better schools, and this may be the source of differential improvements in baccalaureate scores. For example, suppose that the children born before abortion access increased were systematically more likely to end up at cutoffs at which the benefit of going to a better school were smaller; this would introduce 
bias against finding evidence of dynamic complementarities. We show evidence that the distribution of children across cutoffs does not explain our results.

Our findings complement studies that use other settings to test for dynamic complementarities. Aizer and Cunha (2012) exploit exogenous variation in preschool investments from the launch of Head Start to examine complementarities between these investments and early measures of human capital. They show that the effect of preschool enrollment on a subsequent measure of cognitive skill (at 4 years of age) is larger for those children with higher Bailey test scores at 8 months of age. They also present evidence consistent with parental investments reinforcing this pattern. Rossin-Slater and Wust (2015) explore the interaction between a nurse home visiting program and high quality preschool childcare in Denmark. They exploit variation in timing of program implementation and find evidence indicating that these interventions are substitutes rather than complements. Adhvaryu et al. (2015) examine the interaction between parental resources and later educational investments using variation in local rainfall shocks and the Progresa program. They find that educational investments mitigate the negative effects of adverse rainfall shocks. Kaestner and Lubotsky (2014) explore the evolution of skill differences between children using exogenous variation in the timing of school entry, and find patterns that are inconsistent with dynamic complementarities - the initial advantage of children who enter kindergarten early disappears over time. They also note the possibility of behavioral responses on the part of schools, but use comparisons of within-school and between-school estimates to argue that these do not drive their results.

Our paper is also related to previous work discussing the possibility of parental behavior in response to early-life shocks. For example, Royer (2009) notes the challenge of separating the biological effects of low birthweight from parental behaviors due to low birthweight. Black et al. (2007) similarly point out that parents may respond to differences in birthweight across siblings, but find little evidence of such behavior. In addition, in reviewing work on the impact of early childhood environments, Almond and Currie (2011) note that most papers produce reduced form effects which could include either biological effects or responsive parental investments.

Finally, two studies explore whether the impacts of health interventions on educational outcomes are larger for groups that face higher returns to human capital investment. Bhalotra and Venkataramani (2012a) show that the effect of improved water quality in Mexico on cognitive skills is larger for girls than for boys, which is consistent with dynamic complementarities if there are higher returns to investment in girls because of comparative advantage. Bhalotra and Venkataramani (2012b) show that the introduction of sulfa drugs in the U.S. 
had larger impacts for blacks in the North than in the South. This provides similar evidence under the assumption that the greater presence of institutional racism in the South dampened incentives to invest in schooling.

The remainder of the paper proceeds as follows. Section 2 presents a conceptual framework, and Section 3 describes our data. Section 4 provides background on our two sources of variation, and Section 5 presents our empirical strategy. Section 6 presents the results, and Section 7 concludes.

\section{Conceptual Framework}

Analyses of dynamic complementarities must explicitly account for the production of skills at different stages of development. Cunha and Heckman (2007) formalize this by suggesting the following technology for skill formation:

$$
\theta_{t+1}=f_{t}\left(h, \theta_{t}, I_{t}\right)
$$

where $\theta_{t}$ is a vector of skills measured at time $t, h$ stands for parental characteristics, and $I_{t}$ denotes parental investments in child skill made during period $t$. Expression (1) illustrates that skill itself can be an input into the production of skill. Dynamic complementarity arises when this takes the form of higher skill making investments more productive:

$$
\frac{\partial^{2} f_{t}\left(h, \theta_{t}, I_{t}\right)}{\partial \theta_{t} \partial I_{t}}>0 .
$$

2.1. School investments. Our focus is on the interaction between family and school environments; children can be the object of investments in both settings, with the relative importance of the latter likely increasing with age. Since $I_{t}$ refers to family investments, we augment (1) to include school investment, denoted $S$ :

$$
\theta_{t+1}=f_{t}\left(h, \theta_{t}, I_{t}, S_{t}\right)
$$

Our setting provides arguably exogenous shocks to: (a) the stock of skills, $\theta_{t}$, due to the sudden increase in the ease of access to abortion, and (b) school investments, $S_{t}$, due to the rules that govern access to better schools. Thus, if there is complementarity between these, we should find:

$$
\frac{\partial^{2} f_{t}\left(h, \theta_{t}, I_{t}, S_{t}\right)}{\partial \theta_{t} \partial S_{t}}+0 .
$$


To be specific, we will examine the effect of increased access to abortion on later skills. In addition, we will assess the effect of access to better schools. Finally, we will estimate the reduced-form interaction of these effects. We next consider how behavioral responses and changes in composition could affect the interpretation of these reduced-form interactions.

2.2. Behavioral responses. Parents may deliberately choose the human capital investments they direct towards their children (Becker, 1964). For instance, their investments may respond to their children's skill levels, and they may be crowded out or crowded in by school investments:

$$
I_{t}=g_{t}\left(\theta_{t}, S_{t}\right)
$$

For instance, if parents engage in compensatory behavior, investments may depend on the skills children attain relative to their siblings. In addition, there is evidence that parents can react to the level of school inputs (e.g., Das et al., 2013, Del Boca, Flinn, and Wiswall, 2013). In our setting, Pop-Eleches and Urquiola (2013) show that children who just gained access to better schools receive less homework-related help from their parents than children who just missed doing so.

We will explore if such effects take place in a manner that would reinforce or weaken dynamic complementarities. For example, suppose that parents who had easier access to abortion (and whose children on average therefore have higher levels of skill as they transition into high school) lower their effort by more in response to their child's admission to a better school:

$$
\frac{\partial^{2} g_{t}\left(h, \theta_{t}, I_{t}, S_{t}\right)}{\partial \theta_{t} \partial S_{t}}<0
$$

Such an effect would tend to lower the likelihood of finding reduced form evidence of dynamic complementarity even if mechanisms such as those in (2) and (4) are operative. Note that our estimates of behavioral responses may also be influenced by the elasticity of substitution between parental investments across different periods of childhood. For example, if the repeal of the abortion ban led to differences in parental investments that persist past early childhood and continue after children enter high school, our behavioral responses will capture any interaction between these investments and those induced by the shock to school environments.

2.3. Composition effects. Testing for dynamic complementarities, as in (2), requires exogenous variation in $\theta_{t}$, which we claim the change in abortion policy provides. That said, the manner in which this variation originates is relevant for the interpretation of our results. 
To see this, it is useful to write the expression for $\theta_{t+1}$ in recursive form by substituting in for the stock of skills $\theta_{t}$ with all prior investments:

$$
\theta_{t+1}=g_{t}\left(I_{1} \ldots I_{t}, h, \theta_{1}\right)
$$

where $\theta_{1}$ is a child's initial level of skill. This illustrates three potential mechanisms by which increasing access to abortion can affect skills: (i) prior parental investments $I_{1} \ldots I_{t-1}$, (ii) parental characteristics, $h$, and (iii) initial skill endowments, $\theta_{1}$.

All three of these mechanisms are potentially relevant in our context. First, the repeal of the abortion ban is likely to have led to fewer unwanted children and spurred parental investment. This could arise if childbearing that does not occur at an optimal time affects women's educational, marriage, or labor market decisions in ways that lower parental ability to invest in children (Angrist and Evans, 1999, Goldin and Katz, 2002). Alternately, an undesired birth, by raising lifetime fertility, could adversely impact child outcomes through quantity/quality trade-offs (Becker and Lewis, 1973; Becker, 1981). Second, educational outcomes could be affected by changes in the socioeconomic composition of women who carry pregnancies to term, with the direction of the effect depending on which type of women are more likely to use abortion as opposed to other methods of birth control. Specifically, if women of lower socioeconomic status experienced the largest reductions in fertility when access to abortion increased, children born after the liberalization would tend to have more advantaged parents - a composition effect. ${ }^{3}$ Third, it is conceivable that increased access to selective abortions resulted in children with better initial skill endowments $\left(\theta_{1}\right)$ by giving parents greater latitude in deciding which pregnancies to take to term based on factors like fetal health (Grossman and Jacobowitz 1981; Joyce 1987; Grossman and Joyce 1990).

The extent to which these mechanisms are relevant affects the interpretation of the impact of access to abortion and its interaction with access to better schools. While we do not have data on whether the repeal of the abortion ban led to more selective abortions, the screening technology required for this was all but inaccessible for most expectant parents in 1980s Romania. We expect that any differences in initial skill endowments are more likely to reflect parental investments in-utero. In addition, we will present evidence that composition, at least in terms of observables, does not drive our findings. As a result, we will argue that the main channel through which increased access to abortion affected outcomes is greater parental investment.

3 Ananat et al. (2006) suggest the possibility of another source of selection given that changing the cost of abortion will also change pregnancy behavior. We assume that at least in the short period studied immediately after the change in abortion regime there are no changes in marginal pregnancies. 


\section{DATA}

We rely on three types of data: (i) administrative information covering the universe of children who transition from middle to high school, (ii) census data, and (iii) a survey we administered in most towns containing two or three high schools. This section provides background on each of these, including on the rationale for their use.

3.1. Administrative data. Our primary source of information is an administrative database containing all the children who were allocated to a high school in the years 2005 and 2006. These data include their name, date of birth, and allocated school/track. ${ }^{4}$ In addition, they contain each student's transition score; this number determines their priority in admissions to high school (as explained below), and is an unweighted average of their performance in a national $8^{\text {th }}$ grade exam and their middle school grade point average.

We linked these data with information on whether students took the Baccalaureate exam once they were in $12^{\text {th }}$ grade, and on how they performed on it (the 2005 and 2006 admissions cohorts took the exam in 2009 and 2010 respectively). ${ }^{5}$ A satisfactory Baccalaureate grade is a prerequisite for applying to university, and a high grade raises the probability of admission to the most prestigious institutions. ${ }^{6}$

Table 1 presents summary statistics for the main variables used below. Panel A refers to the administrative data and shows that the average transition score among school applicants is 6.6 on a scale of 1 to 10 . About 36 percent of these individuals attend academic high schools, which are more prestigious, with the remaining 64 percent attending other schools. The fraction of students taking the Baccalaureate exam is 53 percent and the average overall grade is 8.3. ${ }^{7}$ Finally, Table 1 also features the Romanian Baccalaureate grade; we consider this component score on its own below, as it is the only subject that all students have to take, and is therefore comparable across schools and tracks.

\footnotetext{
${ }^{4}$ As further explained below, students within each school are allocated to tracks such as Mathematics or Literature.

${ }^{5}$ We merged the admissions and Baccalaureate data by student name/county using a fuzzy matching technique to allow for some misspelling of names. Our conclusions are robust to changing the precision of the matching algorithm, including using only exact matches.

6 The Baccalaureate exam is administered nationally. Students usually take six component tests, with a combination of common subjects (written language, oral language, written foreign language) as well as two track-specific and one elective test. The overall grade is the unweighted average of these scores. The main exam is administered in July. Students are generally not allowed to take the exam early.

7 There are only slight differences in these numbers across the cohorts we consider. In addition, we note that the matched data do not allow us to differentiate between high school dropouts and students who complete high school but do not take the Baccalaureate exam.
} 
TABLE 1. Descriptive statistics

\begin{tabular}{lccc}
\hline \hline & Mean & $\begin{array}{c}\text { Standard } \\
\text { deviation }\end{array}$ & $\mathrm{N}$ \\
\hline Panel A: Administrative data & & & \\
$\quad$ Transition score & 6.60 & 2.23 & 424,929 \\
Average transition score of peers & 6.60 & 1.54 & 424,929 \\
Attend academic high school & 0.36 & 0.48 & 424,929 \\
Baccalaureate taken & 0.53 & 0.50 & 424,929 \\
Baccalaureate grade & 8.33 & 1.00 & 201,912 \\
Romanian Bacc. grade & 7.56 & 1.49 & 225,264 \\
Panel B: Census data (1992) & & & \\
Mother's characteristics & & & \\
$\quad$ Primary education & 0.09 & 0.29 & 86,408 \\
Secondary education & 0.87 & 0.34 & 86,408 \\
$\quad$ Tertiary education & 0.04 & 0.19 & 86,408 \\
$\quad$ Urban region of birth & 0.28 & 0.45 & 86,755 \\
$\quad$ Married & 0.95 & 0.22 & 86,758 \\
$\quad$ Divorced & 0.01 & 0.11 & 86,758 \\
$\quad$ Number of children & 2.29 & 1.93 & 86,774 \\
$\quad$ Age at birth & 25.83 & 6.26 & 86,774 \\
Panel C: Survey data & & & \\
Parent helps with homework & 0.17 & 0.37 & 6,694 \\
Child reports doing homework & 0.62 & 0.49 & 6,758 \\
Parent pays for tutor & 0.30 & 0.46 & 6,723 \\
\hline \hline
\end{tabular}

Notes: Panel A uses administrative data to describe schooling outcomes and characteristics for all children allocated to a secondary school in the years 2005 and 2006 (Source: Romanian Ministry of Education, www.edu.ro). Panel B uses a 15 percent sample of the 1992 census to describe mothers' characteristics; it refers to all women who gave birth in 1991 and 1992. Panel C uses data from a survey we implemented (in most towns with two or three high schools) to describe parental and child behaviors.

3.2. Census data. The administrative data contain little information on children's background, ${ }^{8}$ limiting their usefulness in analyzing whether the increased access to abortion changed the composition of births. We therefore also use the 1992 Census to describe the background characteristics among different birth cohorts. ${ }^{9}$ We focus on: (i) markers of mothers' socio-economic status that are likely to affect children's academic performance, such as education and urban region of birth, and (ii) markers of "unwantedness" that may indicate the children were not planned, such as mothers' marital status, fertility, and age at birth. For instance, an effect of the abortion policy on the age of mothers at birth would be consistent with some children not having been optimally timed under the pre-reform restrictive regime.

\footnotetext{
${ }^{8}$ An exception is an indicator for participating in a scholarship program aimed at students from poor families, which we use below.

${ }^{9}$ Specifically, we use the publicly available 15 percent sample of the 1992 Romanian population census.
} 
While we can only recover maternal characteristics for children living with their mothers, the fact that the census took place in 1992, when children born in 1990 were only about two years old, allows for a match rate exceeding 95 percent. ${ }^{10}$ Table 1 (Panel B) shows that women who gave birth in 1990 and 1991 were on average 26 years old, and had given birth to 2.3 children by 1992. 28 percent of these mothers were born in an urban region. Only 9 percent had primary education (6 years of schooling) or less, 87 percent had secondary education, and the remaining 4 percent held a university degree. Finally, 95 percent of women were married and a negligible fraction were divorced; the remainder were single.

3.3. Survey data. Neither the administrative nor the census data provide detailed information on parent and child behaviors. We therefore implemented a survey that featured parent and student questionnaires. The administrative data provided students' names, but no way of contacting them or their parents. We therefore approached schools and asked their administrators to provide us with the addresses of the students in the 2005 and 2006 cohorts (who were still in school at the time).

We used these addresses to directly approach households. The survey administered to them had three components. First, we interviewed the family head to obtain demographic information on each member of the household. Second, we surveyed the primary caregiver to elicit information on each child. Third, we interviewed the child from the selected schools.

Two factors led us to restrict our target sample to towns containing two or three schools. First, since we needed information from students on either side of admissions cutoffs, it was imperative that all schools in each town agree to participate, and therefore the effort was more likely to encounter problems in larger towns. Second, as shown below the administrative data reveal that the magnitude of the first stages is three to four times larger in smaller towns.

We started with a sample of 38,466 children and 167 schools in the 71 towns with two or three schools. ${ }^{11}$ If any school in a given town declined to participate, we abandoned the whole town. In the end, we obtained complete school surveys and student data from 148 schools in 64 towns; the administrators in these schools provided us with 21,530 addresses. We restricted the target sample further to 138 schools in 59 towns. ${ }^{12}$ Due to financial constraints we randomly sampled 13,408 children out of this population. From this target sample, we obtained 8,400 parent and child surveys. ${ }^{13}$ After restricting the sample to children born in

\footnotetext{
${ }^{10}$ We do not find evidence that the abortion policy changed the probability of living with a parent in 1992.

${ }^{11}$ In Pop-Eleches and Urquiola (2013) the starting sample is larger because the analysis also includes the 2007 cohort.

12 The elimination of five towns reflected that at least one school in each of them, though willing to fill out the school questionnaire, was unable to provide student addresses.

${ }^{13}$ Our response rate of 63 percent is in line with Gallup Romania's (the firm we contracted with) interview rate for this population.
} 
1990 and 1991 who appear in 2005 and 2006 respectively, our final working sample contains 6,771 children. We found no evidence that response rates differed between households with children just above and just below cutoffs.

Table 1 (Panel C) lists the three parental and child behaviors we focus on: whether parents report helping their children with homework, whether children report doing homework, and whether parents report paying for a tutor for their children. ${ }^{14}$ The levels for these variables are 17, 62, and 30 percent, respectively.

To compare the survey towns to the broader sample, Table 7 (in the appendix) presents descriptive statistics from the administrative data for the full sample and the survey subsample (panel A and B, respectively). Panels A.4 and B.4 show that, as expected, the survey towns contain fewer schools and students on average. However, their academic performance is generally comparable to that of children in the full sample (panels A.1 and B.1).

\section{BACKGROUND ON OUR SOURCES OF VARIATION}

This section provides background on the two sources of variation we rely on. It first discusses the 1989 repeal of the abortion ban, and then moves onto the system that allocates students to high schools in Romania. ${ }^{15}$

4.1. The 1989 liberalization of access to abortion. In the 1950s Romania followed the Soviet sphere in providing liberal access to abortion, and this procedure became the main method of birth control used in the country. ${ }^{16}$ As elsewhere in the world, medical practice restricted this procedure to the first trimester of pregnancy. In 1966, the government abruptly outlawed abortion for most women of reproductive age and severely restricted access to other modern methods of contraception. ${ }^{17}$ This policy stance was maintained with minor modifications until the collapse of communism in 1989.

The renewal of access to abortion that took place at that point was equally abrupt, and is the focus of our paper. Specifically, mirroring events in Eastern Europe at the time, civil unrest began in Timisoara in mid-December 1989, and quickly spread to other parts of the country; on December $25^{\text {th }}$, Romania's dictator was executed. On December $26^{\text {th }}$ the interim

\footnotetext{
$\overline{14}$ Private tutoring is common in Romania, as in other countries with high stakes tests.

15 Section 4.1 draws on Pop-Eleches (2006); for further discussion see Kligman (1998). Section 4.2 draws on Pop-Eleches and Urquiola (2013).

16 For instance, in 1965 about four abortions were performed for every live birth in Romania (Berelson, 1979). This approximately inverts the pattern observed at present in the United States, where there are about five live births per abortion (CDC, 2015).

17 Exceptions were made in that women could still access abortion if their age exceeded 42, they had more than four children, or they faced special circumstances involving health problems, rape, or incest.
} 


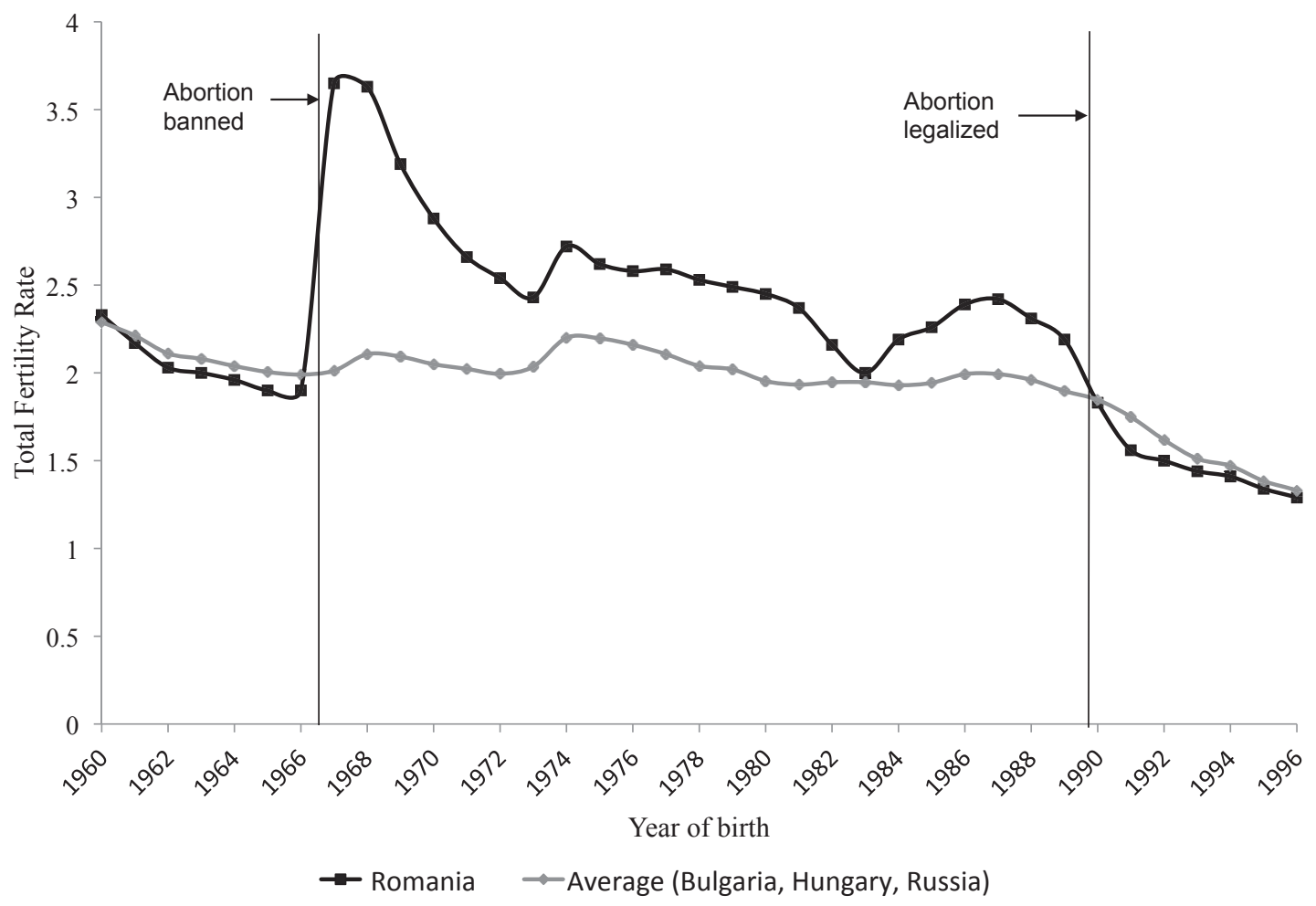

FiguRE 1. Total fertility rate by year

Notes: The figure plots the total fertility rate calculated for each year. The total fertility rate is the number of children each woman would have if she were to live through her childbearing years and have children in accordance with contemporaneous age-specific fertility rates. These data come from various years of the Population and Vital Statistics Report of the United Nations Statistical Division (http://unstats.un.org/unsd/demographic/products/vitstats/default.htm).

leadership abolished the ban on access to abortion, and in January of 1990 it also lifted the ban on the import of modern contraceptives.

Figure 1 illustrates the impact of these measures by plotting the 1960-1996 total fertility rate for Romania as well as for the average of three other Eastern European countries (Hungary, Bulgaria, and Russia) that did not have similar restrictions on the supply of birth control. The vertical lines indicate the years in which abortion was banned and legalized again. Between 1960 and 1966 - to the left of the first vertical line - Romania's total fertility rate tracks the average of the three other countries relatively well. The abrupt jump at the first line shows that the effect of the 1966 ban was dramatic, with the total fertility rate roughly doubling (from about 1.9 to 3.7 children) by 1967. Fertility did decline and stabilize in the years following, although at a higher level. ${ }^{18}$

18 The increase in fertility after 1984 reflects the introduction of further restrictions: (i) stricter monitoring of pregnant women, (ii) an increase in the minimum age at which women qualified for abortions from 42 to 45 years, and (iii) an increase in the analogous threshold in number of children from 4 to 5 . 


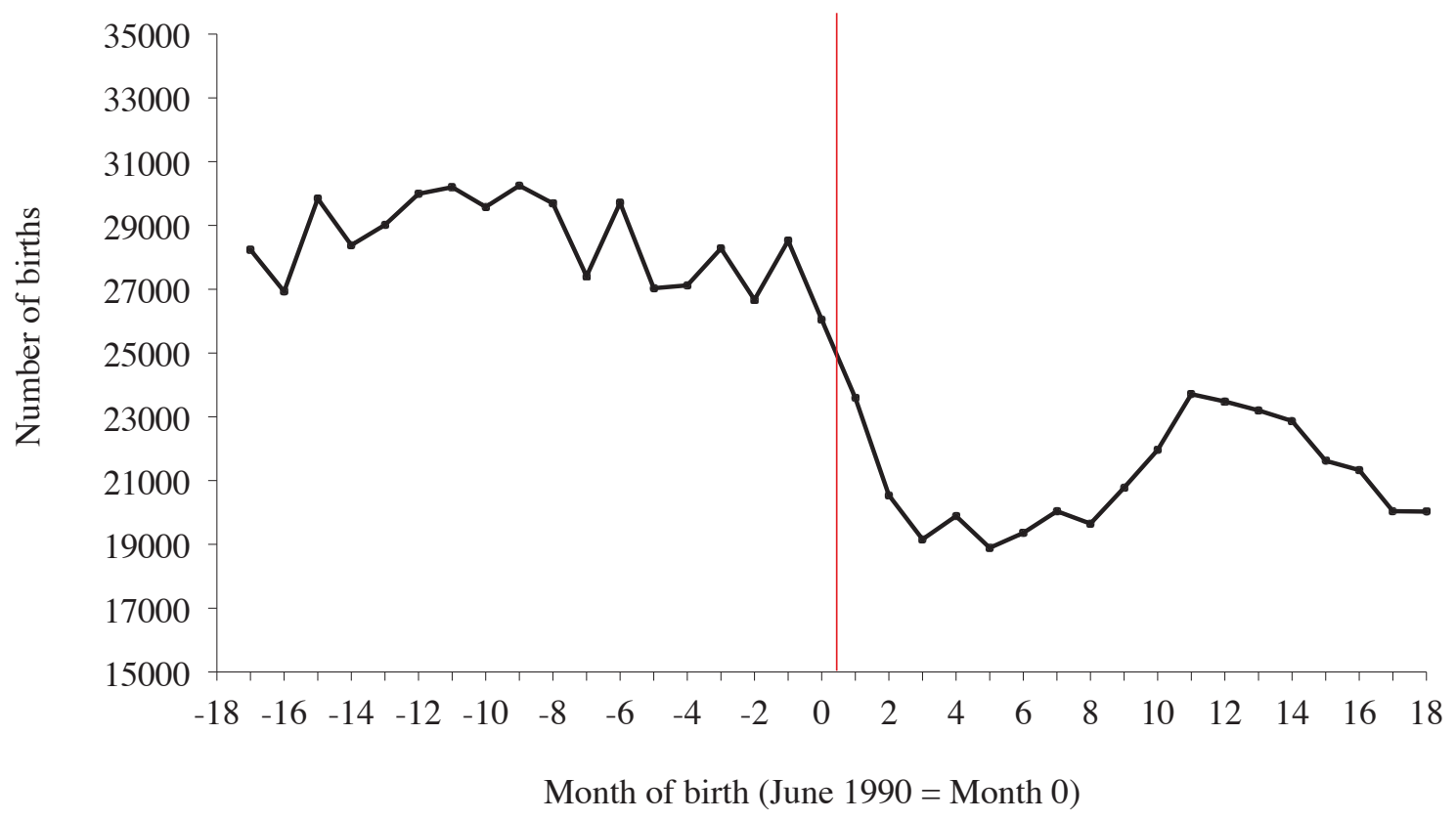

FiguRE 2. Cohort size by month of birth

Notes: The figure uses 1992 census data to plot the number of children born each month. June of 1990 is normalized to zero, and the vertical line indicates the demarcation between June and July of 1990.

Figure 1 also shows an analogous and immediate, if less pronounced, decline in fertility at the second vertical line, following the 1989 liberalization. In addition, one observes a gradual decline between 1992 and 1996, in Romania and in the other three countries. This decline, which also took place in other transition economies, is likely the result of the social and economic transformations following the end of Communism.

Pop-Eleches (2010) argues that the sharp drop in fertility that followed 1989 was driven by the change in access to abortion, and not by changes in access to other methods of birth control, or by changes in the demand for children caused by the transition process. Figure 2 provides further evidence consistent with this. It uses census data to plot the number of children born each month during 1989-1991, with June of 1990 normalized to zero, and a vertical line indicating the demarcation between June and July. It shows that an abrupt drop in fertility began in July of 1990-precisely six months after the point at which expectant mothers in their first trimester could have first accessed abortion. This sudden decline is consistent with the anecdotal evidence; for instance, a Romanian gynecologist reported to us that his hospital was "stormed" by 300 women desiring an abortion on December 27 of 1989. There is no other apparent trend in the number of births over the months featured in 
Figure 2. ${ }^{19}$ Finally, the decline in the size of the monthly birth cohorts is substantial: about 25 thousand births - a one-third reduction.

To summarize, Figure 2 shows that a discrete decline in fertility occurred six months after the repeal of the abortion ban, and is thus consistent with the increased access to abortion driving the lower number of births. Nevertheless, it does not rule out that the decline could be due to other factors provided that they also changed discretely at the end of 1989 .

Pop-Eleches (2010) discusses two candidates. First, the government also introduced pronatalist incentives in 1966. These were small; for instance, they included a one time paid medical leave during pregnancy, a one time maternity grant of about 85 dollars, and a 3 dollar increase in the monthly child allowance. Nonetheless, these incentives might have increased the demand for children and, had they also been repealed in December of 1989, might at least partially account for the pattern observed in Figure 2. The World Bank (1992), reports, however, that there were no major changes in the provision of maternity and child benefits during the months surrounding December $1989 .{ }^{20}$

Second, the fall of the communist regime might have caused people to immediately lower their desired fertility if it led them to drastically update their expectations about the future. While this is intuitively possible, there is little evidence of sudden changes in fertility-related choices in most Eastern European countries. Instead, the consensus among demographers (e.g., David, 1999) is that the decline in fertility during transition was gradual and reflected the continuous worsening of economic conditions. One exception emerges in East Germany, where Chevalier and Marie (2015) document a rapid and temporary decrease in fertility starting in August 1990. They argue that this decline happened about nine months after the fall of the Berlin Wall. Thus, in contrast to the situation in Romania, this decline was due to a reduction in conceptions rather than to post-conception selection. Chevalier and Marie (2015) further point out that in the months immediately after the fall of the Berlin Wall, East Germany abandoned full employment policies and drastically reduced generous child benefits. This is also in contrast to the situation in Romania, where changes in such policies were much more gradual.

Thus, the fact that Romania displays a large decrease in fertility six rather than nine months after the lifting of the abortion ban suggests that the change in access to abortion, rather than a change in the demand for children, accounts for the decline in births. We

\footnotetext{
${ }^{19}$ Also consistent with this, Pop-Eleches (2010) points out that the 1990-1992 period saw no increase in the use of modern contraceptives in Romania.

${ }^{20}$ Of course, the level of social benefits did change later during the transition period in Romania, as it did in most other formerly communist states. This reflected budgetary cuts caused by the severe drop in GDP and might have been a contributing factor to the gradual decrease in fertility during the 1990s (Figure 1).
} 


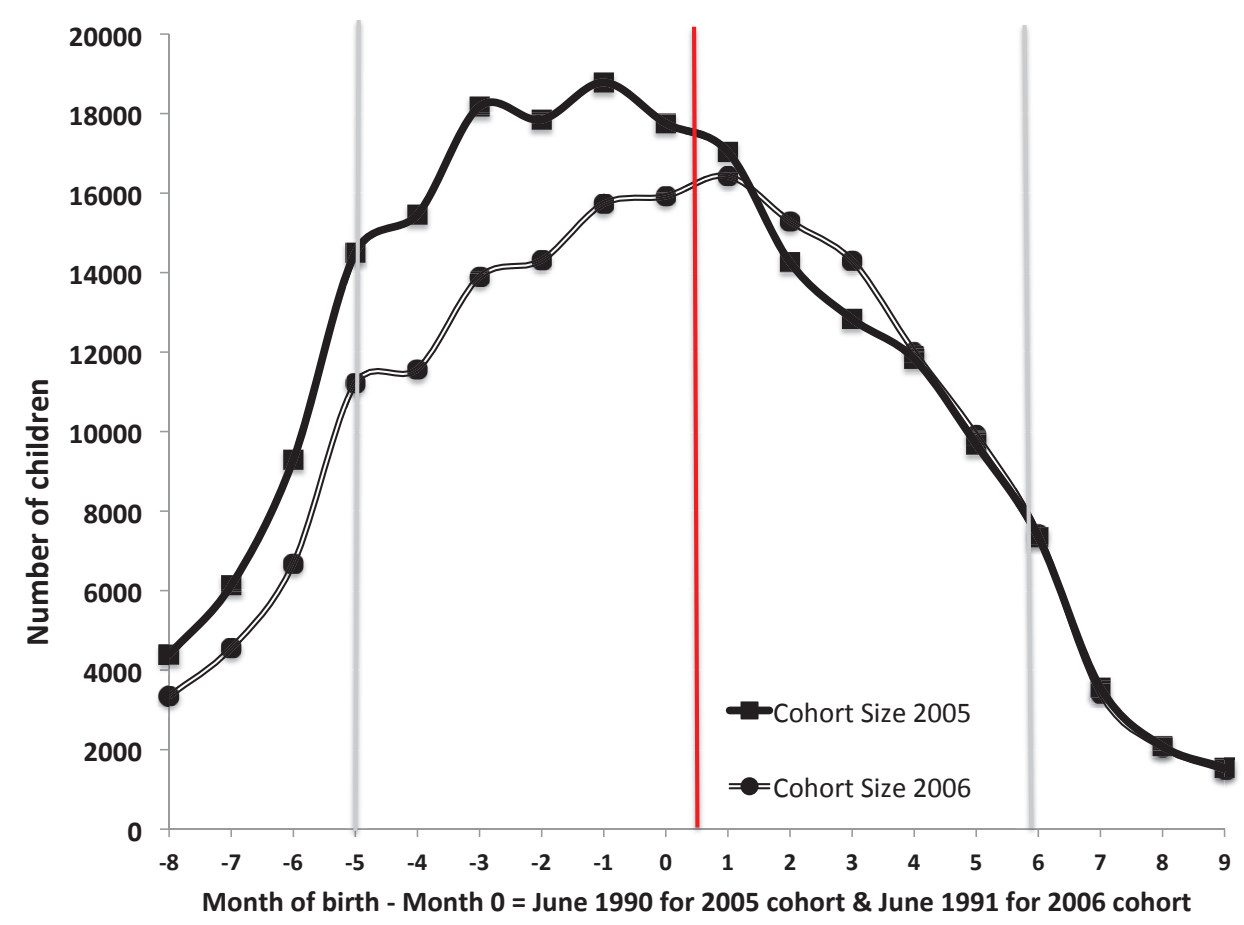

Figure 3. Cohort sizes by month of birth; 2005 and 2006 admission cohorts Notes: This figure uses the administrative data to plot cohort sizes by month of birth. The months covered are October 1989 to March 1991 for the 2005 high school admission cohort, and October 1990 to March 1992 for the 2006 cohort. In each case June is normalized to 0 , and -5 and 6 indicate January and December, respectively. The red, darker vertical line indicates the demarcation between June and July.

will therefore study the children born immediately before and after July of 1990, attributing differences in their outcomes to factors correlated with the increased access to abortion.

Our main birth cohort of interest will be 1990. In addition, we will make use of the 1991 cohort as a control, to account for factors such as seasonality in births. To illustrate, under the rules that govern education in Romania, these cohorts should have enrolled in high school in 2005 and 2006, respectively. Figure 3 uses the administrative data to plot the number of children born in each month for each of these admissions cohorts, with June normalized to 0 (i.e., month 0 is June 1990 for the 2005 admission cohort, and June 1991 for the 2006 cohort). Grey vertical lines indicate January and December (months -5 and 6), and a red, darker vertical line indicates the demarcation between June and July.

Figure 3 raises two observations. First, while the vast majority of children in each application cohort were born in the year expected - that is, they were born between months -5 and 6 - this is not the case for all. For instance, while one expects children enrolling in 2005 to have been born in 1990, some were born in 1989, and fewer in 1991. Graphically, there are large drops in the observed densities at the grey vertical lines, but the densities do not fall to zero. The positive density for months -6 and below reflects that some children repeat 
grades in elementary school if their performance is unsatisfactory; in addition, some parents delay school entry for their children. ${ }^{21}$ The positive and lower density for months greater than 6 reflects that some children begin school early.

The second and more important observation, for our purposes, is that to the left of the dark vertical line indicating the start of July, the 2005 cohort density is everywhere above that of 2006. This reflects that, as implied by Figure 2, there were more births in 1990 before access to abortion was liberalized. To the right of the line - a period with ease of access to abortion for both cohorts - the two densities essentially overlap. ${ }^{22}$

Finally, Figure 4 presents densities of transition scores rather than births; its structure is otherwise similar to that of Figure 3. Two points of note emerge. First, in both application cohorts the children who are above normative age (those to the left of the first gray line) have lower transition scores, consistent with the fact that many of them likely repeated a grade. $^{23}$ Second, and more importantly, is a useful preview of one of our main results: the 2005 application cohort displays lower transition scores among children born immediately before July of 1990 (month 1); no similar difference is evident for the 2006 cohort.

Taken together, Figures 3 and 4 provide prima facie evidence that the increased access to abortion resulted in smaller cohorts with better educational outcomes. In addition, despite the mandated allocation to application cohorts based on date of birth, there may be some selection, and we can address this by using the 2006 admission cohort as a control sample. ${ }^{24}$ Section 5 below formalizes how we use this variation in an empirical strategy.

4.2. The student allocation mechanism. Our second source of variation originates in Romania's high school admission process. The transition between middle school, labeled gymnasium, and high school results in an unusually systematic allocation of students to schools. ${ }^{25}$ Every child who completes middle school receives a transition score which equally weights: (i) her performance in a national $8^{\text {th }}$ grade exam covering Language, Math, and History/Geography, ${ }^{26}$ and (ii) her middle school grade point average.

21 This happens especially among children born close to the enrollment cut-offs. It is analogous to the "red-shirting" behavior observed in the U.S.

${ }^{22}$ To be precise, there is a slightly sharper decrease in the cohort size after Month 1 for the 2005 cohort.

23 There is also a dip in average grades for children born around December (month 6). This is likely a result of month of birth effects, and that children who were sent to school earlier than required by the law might be different from the average population.

${ }^{24}$ We did not find any references indicating institutional changes at the high school level in Romania (both in terms of the structure of the school system or the rules of the admission process) between 2005 and 2006.

25 During the period we study, schooling in Romania was compulsory until the $10^{\text {th }}$ grade. As a result the entire cohort of students who complete middle school is required to participate in this allocation process.

26 All tests and grades use a scale ranging from 1 to 10 , with a passing grade of 5 . Students who score below 5 are not allowed to apply to high school, but can enroll in vocational school. 


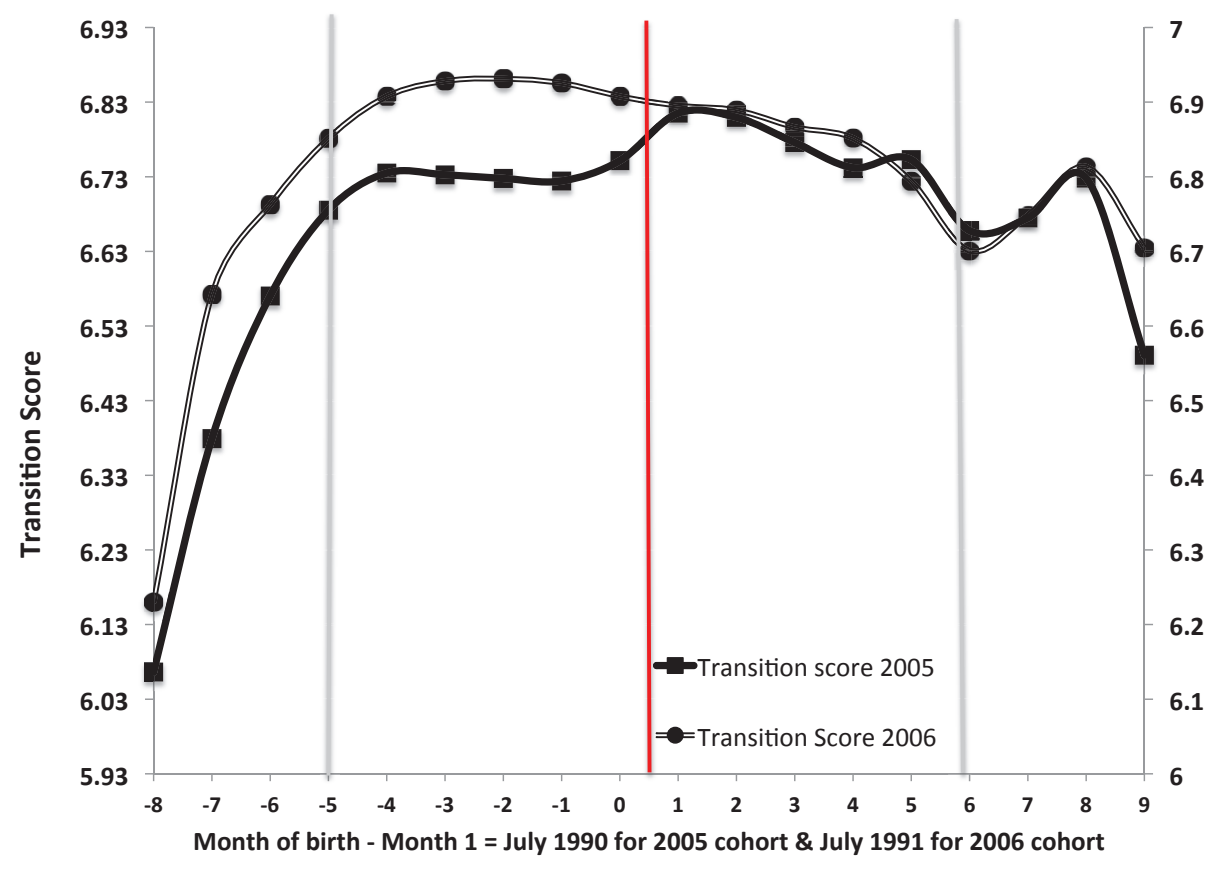

FiguRE 4. Average transition score by month of birth; 2005 and 2006 cohorts Notes: This figure uses the administrative data to plot average transition scores by month of birth. The months covered are October 1989 to March 1991 for the 2005 high school admission cohort, and October 1990 to March 1992 for the 2006 cohort. In each case June is normalized to 0, and -5 and 6 indicate January and December, respectively. The red, darker vertical line indicates the demarcation between June and July.

After receiving their transition scores, students must submit a list of ranked choices specifying combinations of: (i) a high school, and (ii) one of seven academic tracks: Mathematics, Natural Sciences, Technical Studies, Services, Social Studies, Literature, and Natural Resources and Environmental Protection. These tracks operate as "schools within a school," since students in each track take all their coursework together and do not take classes with members of other tracks - although they share infrastructure and a principal, and may share teachers. Not all schools offer all tracks, but all must submit their track-specific capacities in advance, and these are public information.

Students' choices are expressed through an application form submitted via their middle schools to the Ministry of Education. Using a computerized system, the Ministry then ranks students by their transition score - no other criteria (e.g., sibling preferences or geographic proximity) are considered. The mechanism considers the highest ranked student and assigns her to her most preferred school/track. It then treats the second-ranked similarly. Eventually, the procedure will reach a student whose first choice is full. If this happens, it tries to assign the student to her second choice; if that one is full as well, then to the third, and 
so on. Only once this student has been assigned does the mechanism move onto the next person. ${ }^{27}$ Students thus have incentives to truthfully reveal their preference rankings. ${ }^{28}$

Schools must enroll the children in the admission list returned from the computerized allocation. ${ }^{29}$ In most markets the result of this process is a clear hierarchy of schools by average peer quality. As stated above, for simplicity we will label higher ranked schools as "better" schools. ${ }^{30}$

Finally, we note that when we analyze the effects of having access to a better school, we impose three sample restrictions on the administrative data. The first two reflect that, as explained below, we rank schools and set cutoff scores under the assumption that towns are self-contained markets. ${ }^{31}$ We therefore omit the capital, Bucharest, which is composed of six towns the borders of which students can cross with relative ease. We do not find this omission to affect our key conclusions. Second, when our analysis focuses on between-school cutoffs, we omit towns that have only one high-school. ${ }^{32}$ Third, we drop all students who enroll in the vocational sector; this precludes their access to higher education and hence we do not observe Baccalaureate outcomes for them. ${ }^{33}$

${ }^{27}$ Some students only request school-track choices with minimum entry scores above their own transition score. These individuals are assigned, in a second round, to schools/tracks that did not fill. Students are warned against this outcome and allowed to submit a list of choices of essentially unlimited length. As a result, for example, in 2007 only 1.1 percent of applicants moved to the second round.

28 The existing legislation does not allow children to decline their initial assignment, although in rare situations children do manage to switch schools and/or tracks over the years. Such switching does not pose a threat to our "intent-to-treat" research design, which as discussed below, is based on the assigned school/track.

${ }^{29}$ One concern with the administrative data arises if the participation of children in the high school allocation process is affected by the lifting of the abortion ban. The direction of the bias is likely to be downward if children born under the ban have higher dropout or grade repetition rates in primary school and therefore do not take the high school admissions exam. However, we can show that this source of selection is unlikely to play a major role. Figure 7 (in the appendix) uses the census data to show that the proportion of children born in each month of 1990 who are present in the 2005 high school cohort is quite similar to the proportion of children born in each month of 1991 who are present in the 2006 high school cohort.

${ }^{30}$ Pop-Eleches and Urquiola (2013) show that school level peer quality is correlated, in the expected directions, with factors like parental involvement and perceptions of quality on the part of parents and school prinicipals. Nevertheless, rankings by characteristics like peer quality need not correlate with value added, as suggested by Abdulkadiroglu et al. (2014) and MacLeod and Urquiola (2015).

${ }^{31}$ We use the term town to denote a high school market. The term that appears in the administrative data is locality (Localitate, in Romanian). In most cases these units actually correspond to cities/towns. In a few, they denote the largest of a number of small towns or villages - the town which actually contains the high school that might draw from a corresponding catchment area composed of smaller towns or villages.

32 Despite these omissions, for simplicity we will describe the sample as covering "all towns" unless we focus only on those towns covered by our specialized survey.

33 The omission of students who enroll in vocational tracks could be problematic if the probability of enrolling is affected by options in non-vocational schooling. We nonetheless decided to drop these students because it is very unlikely that a large proportion of students would prefer to attend a vocational track over a nonvocational track. We have explored the actual school/track choices as collected ex-post in our survey sample. These responses may suffer from ex-post rationalization, but it is worth noting that less than one percent of 


\section{EMPIRICAL STRATEGY}

This section presents our empirical strategy in three steps. First, it describes the differencein-difference (DD) framework we use to estimate the impact of access to abortion. Second, it describes the regression discontinuity (RD) approach we use to estimate the effects of access to a better school. Third, it merges these into a combined RD-DD framework that allows us to estimate reduced-form interactions between the increased access to abortion and access to a better school.

5.1. The impact of access to abortion. The first step is to estimate how the increase in access to abortion affected educational outcomes. Consider the following regression:

$$
y_{i t}=\beta_{0}+\beta_{1} \text { Access }_{i t}+\beta_{2} \text { trend }_{i}+\beta_{3} \text { cohort }_{t}+\epsilon_{i t},
$$

where $y_{i t}$ is an outcome measured either upon applying to or upon finishing high school - the transition and Baccalaureate scores, respectively. Access $A_{i t}$ stands for access to abortion and is equal to 1 if individual $i$ was born after July 1, 1990, which is six months after access to abortion increased and the point at which the decrease in fertility is first observed (Section 3). trend $_{i}$ is a quadratic polynomial in the month of birth, and cohort $t_{t}$ takes on a value of one for children in the 2006 admission cohort, and of zero for children in the 2005 cohort. The overall impact of the change in abortion legislation is captured by $\beta_{1}$, where standard errors are clustered by age in months (Bertrand, Duflo, and Mullainathan, 2004).

We also consider three alternative specifications: (i) including only the 2005 cohort, (ii) replacing the trend $_{i}$ controls with a set of calendar month of birth dummies, and (iii) replacing the trend $_{i}$ controls with an indicator variable for being born in the first six months of a calendar year. Formally:

$$
\begin{gathered}
y_{i t}=\eta_{0}+\eta_{1} \text { Access }_{i t}+\eta_{2} \text { trend }+\epsilon_{i t} \\
y_{i t}=\gamma_{0}+\gamma_{1} \text { Access }_{i t}+\gamma_{2} \text { month }_{i t}+\gamma_{3} \text { cohort }_{i t}+\epsilon_{i t} \\
y_{i t}=\delta_{0}+\delta_{1} \text { Access }_{i t}+\delta_{2} \text { before }+\delta_{3} \text { cohort }_{i t}+\epsilon_{i t}
\end{gathered}
$$

where (7) applies only to the 2005 admission cohort, month is a set of eleven month of birth dummies, and before is a dummy for birth between January and June inclusive.

students who attend a non-vocational track claim that they ranked a vocational track above their assigned track. For further information on vocational education in Romania, see Malamud and Pop-Eleches (2010). 
To summarize, our approach essentially compares the outcomes of children born in the six months before and after the drop in fertility that occurred after July 1, 1990. The trend controls account for effects that are associated with age and vary continuously, and the 2006 cohort accounts for possible month of birth effects (e.g., associated with seasonality) as well as selection of a birth cohort into a corresponding high school admission cohort (Figure 3). ${ }^{34}$ We note that equation (9) corresponds to the "classic" difference in differences specification (Meyer, 2005).

Finally, in our baseline implementation these specifications do not include controls. In robustness checks, we explore specifications that feature: (i) an indicator of poverty status present in the adminstrative data, and (ii) measures of parental characteristics present in the survey data. These aim to control for possible compositional changes.

5.2. The impact of access to a better school. The second step of our analysis estimates the impact of access to a better school. Although students can request any high school in the country, we suppose that they restrict their choices to the towns they live in, a reasonable assumption since the applicants are 13-14 year olds typically living with their parents. Within each town, we rank schools and school/tracks (in separate exercises) according to their average score, and set the cutoffs equal to their minimum scores. ${ }^{35}$ In other words, we set each school's (or school/track's) cutoff equal to the score of the child with the lowest transition score. ${ }^{36}$

This yields more than one thousand potential discontinuities. In this section we first discuss the conceptual basis for analyzing any given one of these experiments, focusing on schools for simplicity. We then describe how we go about summarizing them.

5.2.1. A single between-school cutoff. Consider a town in which $i$ indexes students and $s=1, \ldots, S$ indexes schools, where the latter have been ordered from the worst to the best in terms of their average transition score. Additionally, let $z=1, \ldots,(S-1)$ index cutoffs, such that, for example $z=1$ denotes the cutoff between the worst and next-to-worst school

$\overline{34}$ All specifications are restricted to children who are in their normative admission cohort based on their date of birth; that is, children born in 1990 (1991) present in the 2005 (2006) high school cohort.

${ }^{35}$ We also implemented the exercise ranking schools and tracks by their minimum score, with similar results.

${ }^{36}$ Using the minimum admission score is in line with our "intent-to-treat" approach in that only schools that reach capacity will generate meaningful first stages. An alternative approach would have been to set each school's (or school/track's) cutoff equal to the transition score of the child that fills its last slot. We could potentially identify that child since classes are limited to 28 slots (e.g., the track-specific slot availabilities which schools submit prior to the allocation process must be multiples of 28). However, our process for collecting and matching the administrative files (from hundreds of thousands of web pages) creates some measurement error. This limits our ability to determine with certainty if a school reached capacity. Nevertheless, using some approximations, we estimate that excluding the bottom ranked school in each town, the percent of schools that reach capacity ranges, depending on the cohort, between 80 and 90 percent. 
in the town, and $z=(S-1)$ indicates the cutoff between the top-ranked school and the next best. Let $t_{i}$ denote student $i$ 's transition score, and $\tilde{t}_{z}$ be the minimum grade required for admission into the better of the two schools indexed by $z \cdot{ }^{37}$

Consider the specfication:

$$
y_{i}=\alpha 1\left\{t_{i}-\tilde{t}_{z} \geq 0\right\}+a\left(t_{i}\right)+\varepsilon_{i}
$$

where $y_{i}$ is Baccalaureate performance for student $i, 1\left\{t_{i}-\tilde{t}_{z} \geq 0\right\}$ is an indicator for whether a student's transition score is greater than or equal to the cutoff indexed by $z$, and $a\left(t_{i}\right)$ is a flexible control function for the transition score.

If access to a better school changes discontinuously at $\tilde{t}_{z}$, then the causal impact of this access can be identified even if students' transition scores are systematically related to factors that affect outcomes like Baccalaureate grades. Intuitively, suppose the transition score is smoothly related to characteristics that affect achievement, i.e., $a(t)$ is constant in a small enough neighborhood around the cut-off. Under this assumption, students with scores just below $\tilde{t}_{z}$ provide an adequate control group for individuals with scores just above, and any difference in their outcomes can be attributed to the fact that they have access to schools of different quality - i.e., $\alpha$ is non-parametrically identified at $\tilde{t}_{z}$ (Hahn, Todd, and van der Klauuw, 2011). More generally, if $a(t)$ is specified correctly, it will capture the dependence of outcomes on the transition score away from the cut-off, and one can use all the data to estimate (10).

We use specifications like (10) to produce "intent-to-treat" estimates of the effect of having access to a higher-ranked school. Our "first stage" results show that a significant proportion of children who have access to a better school take it up. This allows us to measure the net effect of such access on children's outcomes. It is, however, impossible to attribute the effect to a single channel, since multiple aspects of school quality change at the cutoffs, in addition to possible behavioral responses on the part of students, parents, teachers, etc.

5.2.2. Summarizing information for many cutoffs. The above specifications illustrate how one might exploit one cutoff. As stated, our data contain over one thousand. In order to summarize these, and for the sake of statistical power, we focus on regressions which pool data across cutoffs, relying on the fact that $t_{i}-\tilde{t}_{z}$ measures the distance between each cutoff and the transition score of each student in a town. Specifically, we "stack" the data such that every student in a town serves as an observation for every cutoff, and (when observations are used more than once) run the analyses clustering at the relevant level. Including

$\overline{37}$ We abuse notation as above $t$ denoted a time period; henceforth it stands for the transition score. 
all observations for every cutoff is relevant in that, for example, the student with the best score in town could successfully request any school. In fact, regressions restricted to students in bands close to the cutoffs rarely use student-level observations more than once.

Specifically, most of our reduced form regressions are specified as follows:

$$
y_{i}=\alpha 1\left\{t_{i}-\tilde{t}_{z} \geq 0\right\}+\eta\left(t_{i}-\tilde{t}_{z}\right)+\psi\left(t_{i}-\tilde{t}_{z}\right) * 1\left\{t_{i}-\tilde{t}_{z} \geq 0\right\}+w_{z}+v_{i},
$$

that is, a regression of outcomes on a dummy for whether a student's transition score is greater than or equal to the cutoff, along with controls that include: (i) a linear spline in students' grade distance to the cutoff, one which allows the slope to vary on each side of the cutoff, and (ii) a full set of cutoff dummies, $w_{z} \cdot{ }^{38}$

Finally, to simplify notation, equation (11) can be written as:

$$
y_{i}=\eta_{0}+\eta_{1} \text { Access }_{i}+\eta_{2} \text { score }_{i}+\eta_{3} \text { score }_{i} * \text { Access }_{i}+u_{i},
$$

where $A c c e s s B_{i}$ stands for access to a better school and is a dummy equal to one when a student's transition score is greater than or equal to the cutoff; score $e_{i}$ is the running variable and score $_{i} *$ above $_{i}$ is the interaction to allow for the linear spline; the cutoff fixed effects are now implicit.

5.3. Estimating interactions between family and school environments. The third and final step is to combine the above two approaches to estimate potential interactions between family and school environments. We merge the difference-in-differences (DD) and the regression discontinuity (RD) design into an RD-DD framework. We begin by discussing the intuition behind this approach, and then present the full interacted specification.

5.3.1. Intuition. The increase in access to abortion defines four groups as captured in Figure 3: (i) those born July-December, 1990, (ii) those born January-June, 1990, (iii) those born July-December, 1991, and (iv) those born January-June, 1991. Figure 3 shows that group (ii) contains distinctly more children and likely the highest share of unwanted children.

One can estimate the impact of access to a better school within each of these groups - i.e., one can estimate $\eta_{1}$ (equation 12) within each group, learning about the average effect of school quality from hundreds of cutoffs in each case. These estimates provide information

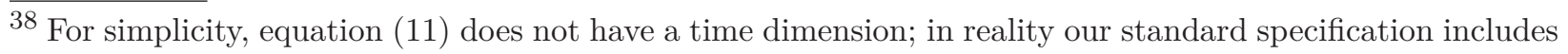
a full set of cutoff*year dummies. 
on the interaction between our environments of interest. For instance, a positive difference

$$
\eta_{1}^{J u l y-D e c, 1990}-\eta_{1}^{J a n-J u n, 1990}
$$

would provide prima facie evidence of dynamic complementarity, as it suggests that the effect of access to a better school is higher among children who had higher skill upon entering high school because their parents had easier access to abortion.

A difference like (13) could be driven by factors like seasonality, and one can therefore use groups (iii) and (iv) to control for such factors, calculating a difference in differences effect:

$$
\left(\eta_{1}^{\text {July-Dec,1990 }}-\eta_{1}^{\text {Jan-Jun,1990 }}\right)-\left(\eta_{1}^{\text {July-Dec,1991 }}-\eta_{1}^{\text {Jan-Jun,1991 }}\right)
$$

Below we will present such an estimate.

5.3.2. Fully interacted specification. The above intuition is formalized in a fully interacted specification:

$$
\begin{aligned}
Y_{i} & =\lambda_{0}+\lambda_{1} \text { Access }_{i}+\lambda_{2} \text { trend }_{i}+\lambda_{3} \text { cohort }_{i}+\lambda_{4} \text { Access }_{i}+\lambda_{5} \text { score }_{i} \\
& +\lambda_{6} \text { score }_{i} * \text { Access }_{i}+\lambda_{7} \text { Access }_{i} * \text { Access }_{i}+\lambda_{8} \text { Access }_{i} * \text { score }_{i} \\
& +\lambda_{9} \text { Access }_{i} * \text { score }_{i} * \text { Access }_{i}+\lambda_{10} \text { trend }_{i} * \text { Access }_{i}+\lambda_{11} \text { trend }_{i} * \text { score }_{i} \\
& +\lambda_{12} \text { trend }_{i} * \text { score }_{i} * \text { Access }_{i}+\lambda_{13} \text { cohort }_{i} * \text { Access }_{i}+\lambda_{14} \text { cohort }_{i} * \text { score }_{i} \\
& +\lambda_{15} \text { cohort }_{i} * \text { score }_{i} * \text { Access }_{i}+w_{i}+\mu_{i}
\end{aligned}
$$

which will be our base specification. The coefficient of interest is $\lambda_{7}$, the interaction between Access $_{i}$ and $A_{\text {ccess }} B_{i}$. This essentially estimates whether the impact of having access to a better school is larger for children who experienced better family environments because they were born after access abortion increased. Our base implementation of (15) will use data from both the 2005 and 2006 school entry cohorts. We will also present results with alternative specifications that: (i) include only the 2005 cohort, (ii) use a set of calendar month of birth dummies to model time trends, or (iii) replace the trend controls with an indicator variable for being born in the first six months of a calendar year.

Given that the transition score is the running variable in our RD design, and given that this score is affected by the abortion policy, it might appear that our empirical strategy involves controlling for a "post-treatment" variable. However, we note that we do not control for the transition scores across treatment groups (i.e. the four groups in our DD specification); we control for transition scores within each group. This is most obvious when we explicitly obtain an RD estimate separately by group, but it is also true in the interacted RD-DD 
specification because we allow for different intercepts for each group. Moreover, the fact that we have over one thousand discontinuities implies that wanted and unwanted children are spread over the entire range of the transition score distribution.

We also use specification (15) to examine behavioral responses among survey respondents, along dimensions such as child and parent effort around homework. In this case the coefficient on the interaction between Access $_{i}$ and $A c c e s s B_{i}$ provides information on whether families of children born after the increased access to abortion respond differently in terms of effort when given the opportunity to access a better school.

\section{Results}

This section first presents results that examine the impact of access to abortion on educational outcomes. It then presents results on the impact of access to a better school. Finally, it uses our combined RD-DD framework to explore interactions between the two.

6.1. The impact of access to abortion. The impact of access to abortion is summarized in Table 2. The columns feature six indicators of educational achievement and school quality, and panels A, B, C and D show the coefficient on Access $A_{i}$ in four different specifications. Panel A restricts the sample to children born in 1990 who applied to high school in 2005, and uses quadratic functions of their month of birth to control for seasonality. Panel B adds the children born in 1991 who applied to high school in 2006, includes a cohort dummy, and replaces the quadratic trends with an indicator variable for being born in the first six months of the calendar year. Panel C is our preferred specification; like Panel B it includes children in both admissions cohorts and a cohort dummy, and like Panel A it includes a quadratic in month of birth. Finally, Panel D uses both birth cohorts but includes a set of calendar month of birth dummies instead of the quadratic in the month of birth.

All the coefficients in Table 2 are positive, and 22 out of 24 are statistically significant. The robustness of this result provides strong evidence that increased parental access to abortion improved children's educational outcomes. Our preferred specifications in Panel C show that children who were born after access to abortion was liberalized on average had transition scores that were 0.1 points higher. This enabled them to gain admission to schools with peers whose transition scores were on average 0.04 points higher. ${ }^{39}$ In addition, they were two percentage points more likely to attend an academic high school (from a baseline

\footnotetext{
39 The average test score of the 2006 cohort is slightly higher than that of the 2005 cohort, and one might therefore worry that an equal point increase in performance might have a different impact across the two cohorts in terms of how far a student moves along the ability distribution. In such a situation a more appropriate specification might use the log of the admission score. In regressions not reported we find this does not affect our key results.
} 
TABLE 2. The effect of access to abortion on educational outcomes

\begin{tabular}{|c|c|c|c|c|c|c|}
\hline & $\begin{array}{l}\text { Transition } \\
\text { score }\end{array}$ & $\begin{array}{l}\text { Average } \\
\text { transition } \\
\text { score } \\
\text { of peers } \\
(2) \\
\end{array}$ & $\begin{array}{l}\text { Attend } \\
\text { academic } \\
\text { high } \\
\text { school } \\
(3)\end{array}$ & $\begin{array}{c}\text { Baccalaureate } \\
\text { taken }\end{array}$ & $\begin{array}{c}\text { Baccalaureate } \\
\text { grade }\end{array}$ & $\begin{array}{l}\text { Romanian } \\
\text { bacc. Grade }\end{array}$ \\
\hline \multicolumn{7}{|l|}{ Panel A: 2005 cohort } \\
\hline Abortion access (Access $A)$ & $\begin{array}{c}0.091 * * * \\
{[0.014]}\end{array}$ & $\begin{array}{c}0.056 * * * \\
{[0.012]}\end{array}$ & $\begin{array}{c}0.017 * * * \\
{[0.002]}\end{array}$ & $\begin{array}{c}0.054 * * * \\
{[0.011]}\end{array}$ & $\begin{array}{c}0.042 * * * \\
{[0.009]}\end{array}$ & $\begin{array}{c}0.025 * * * \\
{[0.006]}\end{array}$ \\
\hline Monthly trend & $\mathrm{Y}$ & $\mathrm{Y}$ & $\mathrm{Y}$ & $\mathrm{Y}$ & $\mathrm{Y}$ & $\mathrm{Y}$ \\
\hline Calendar month dummies & $\mathrm{N}$ & $\mathrm{N}$ & $\mathrm{N}$ & $\mathrm{N}$ & $\mathrm{N}$ & $\mathrm{N}$ \\
\hline Cohort dummy & $\mathrm{N}$ & $\mathrm{N}$ & $\mathrm{N}$ & $\mathrm{N}$ & $\mathrm{N}$ & $\mathrm{N}$ \\
\hline $\mathrm{N}$ & 175,506 & 175,506 & 175,506 & 175,506 & 89,865 & 98,462 \\
\hline \multicolumn{7}{|c|}{ Panel B: 2005 and 2006 cohorts } \\
\hline Abortion access $(\operatorname{Access} A)$ & $\begin{array}{c}0.104 * * * \\
{[0.0304]}\end{array}$ & $\begin{array}{c}0.0362 * \\
{[0.0196]}\end{array}$ & $\begin{array}{c}0.0213 * * * \\
{[0.00486]}\end{array}$ & $\begin{array}{c}0.0461 * * * \\
{[0.0141]}\end{array}$ & $\begin{array}{c}0.0226^{*} \\
{[0.0120]}\end{array}$ & $\begin{array}{l}0.00935 \\
{[0.0107]}\end{array}$ \\
\hline Monthly trend & $\mathrm{N}$ & $\mathrm{N}$ & $\mathrm{N}$ & $\mathrm{N}$ & $\mathrm{N}$ & $\mathrm{N}$ \\
\hline Calendar month dummies & $\mathrm{N}$ & $\mathrm{N}$ & $\mathrm{N}$ & $\mathrm{N}$ & $\mathrm{N}$ & $\mathrm{N}$ \\
\hline Cohort dummy & $\mathrm{Y}$ & $\mathrm{Y}$ & $\mathrm{Y}$ & $\mathrm{Y}$ & $\mathrm{Y}$ & $\mathrm{Y}$ \\
\hline $\mathrm{N}$ & 336,004 & 336,004 & 336,004 & 336,004 & 171,902 & 191,160 \\
\hline \multicolumn{7}{|c|}{ Panel C: 2005 and 2006 cohorts } \\
\hline Abortion access (Access $A)$ & $\begin{array}{c}0.101 * * * \\
{[0.0113]}\end{array}$ & $\begin{array}{l}0.0419 * * * \\
{[0.00780]}\end{array}$ & $\begin{array}{l}0.0196 * * * \\
{[0.00234]}\end{array}$ & $\begin{array}{l}0.0513 * * * \\
{[0.00613]}\end{array}$ & $\begin{array}{l}0.0284 * * * \\
{[0.00764]}\end{array}$ & $\begin{array}{c}0.0121 * \\
{[0.00633]}\end{array}$ \\
\hline Monthly trend & $\mathrm{Y}$ & $\mathrm{Y}$ & $\mathrm{Y}$ & $\mathrm{Y}$ & $\mathrm{Y}$ & $\mathrm{Y}$ \\
\hline Calendar month dummies & $\mathrm{N}$ & $\mathrm{N}$ & $\mathrm{N}$ & $\mathrm{N}$ & $\mathrm{N}$ & $\mathrm{N}$ \\
\hline Cohort dummy & $\mathrm{Y}$ & $\mathrm{Y}$ & $\mathrm{Y}$ & $\mathrm{Y}$ & $\mathrm{Y}$ & $\mathrm{Y}$ \\
\hline $\mathrm{N}$ & 336,004 & 336,004 & 336,004 & 336,004 & 171,902 & 191,160 \\
\hline \multicolumn{7}{|c|}{ Panel D: 2005 and 2006 cohorts } \\
\hline Abortion access (Access $A)$ & $\begin{array}{c}0.104 * * * \\
{[0.00807]}\end{array}$ & $\begin{array}{l}0.0356 * * * \\
{[0.00508]}\end{array}$ & $\begin{array}{l}0.0211 * * * \\
{[0.00227]}\end{array}$ & $\begin{array}{l}0.0456 * * * \\
{[0.00370]}\end{array}$ & $\begin{array}{l}0.0230 * * * \\
{[0.00547]}\end{array}$ & $\begin{array}{c}0.0094 \\
{[0.00669]}\end{array}$ \\
\hline Monthly trend & $\mathrm{N}$ & $\mathrm{N}$ & $\mathrm{N}$ & $\mathrm{N}$ & $\mathrm{N}$ & $\mathrm{N}$ \\
\hline Calendar month dummies & $\mathrm{Y}$ & $\mathrm{Y}$ & $\mathrm{Y}$ & $\mathrm{Y}$ & $\mathrm{Y}$ & $\mathrm{Y}$ \\
\hline Cohort dummy & $\mathrm{Y}$ & $\mathrm{Y}$ & $\mathrm{Y}$ & $\mathrm{Y}$ & $\mathrm{Y}$ & $\mathrm{Y}$ \\
\hline $\mathrm{N}$ & 336,004 & 336,004 & 336,004 & 336,004 & 171,902 & 191,160 \\
\hline Mean of dependent variable & 6.60 & 6.60 & 0.36 & 0.53 & 8.33 & 7.56 \\
\hline
\end{tabular}

Notes: Standard errors are in brackets and are clustered by age in months. The abortion access dummy (Access $A$ in equation (6)) equals 1 for individuals born on or after July 1, 1990, and equals 0 for individuals born on or before June 30, 1990. Panel A includes children born in 1990 and present in the 2005 high school admission cohort. Panels B, C and D also include children born in 1991 and present in the 2006 cohort as controls. The monthly trend is a quadratic in month of birth. ${ }^{*} p<0.10,{ }^{* *} p<0.05,{ }^{* * *} p<0.01$.

mean of 36 percent). Analogous positive impacts are observed four years later when these children reached the Baccalaureate exam. Children born after access to abortion increased are 5.1 percentage points more likely to take the exam and, conditional on doing so, score 0.03 and 0.01 standard deviations higher overall and in the Romanian language component, respectively. These final three are the main measures of achievement we will use below. ${ }^{40}$

$\overline{40}$ We performed a number of additional robustness checks not reported here. One potential concern with the results in Table 2 is that our estimates may depend on how we control for trends and seasonal factors. One alternative is to restrict our analysis to much narrower time windows. The simplest comparison is the difference in educational outcomes for children born in July and June of 1990. The difference in the average 
For further illustration Figure 5 plots residuals from regressions similar to those in Panel D of Table 2, for the months of January to December of 2005. The graphs for all six outcome variables, while displaying some noise, show a visible break in the pattern of educational achievement after July of 1990. They provide complementary evidence that children born after the repeal of the abortion ban had better educational outcomes.

6.2. The impact of going to a better school. We now turn to the impact of our second source of variation: access to a better school. As is common in RD-based analyses, we begin with a graphical illustration of our results. Panel A in Figure 6 illustrates the basic first stage result, pooling all between-school cutoffs. The x-axis plots students' transition scores relative to the cutoffs that allow access a better school; the y-axis describes the peer quality that students experience, as measured by the mean transition score at their respective school. The mean transition score is collapsed into cells containing individuals who are within 0.01 points of each other. Panel B is structured similarly, but the y-axis is based on residuals from a regression of the mean transition score on cutoff fixed effects. Both panels suggest that the average peer quality experienced by students rises significantly and discontinuously when their transition score crosses a score cutoff. In other words, on average students do use the opportunity to attend a better school. The vertical distance between the points close to the discontinuity corresponds to the estimate of $\eta_{1}$ in expression (12).

Table 3, Panel A presents the regression analog to these two panels. Column (1) restricts the sample to children within one point of the cutoff-about 0.9 million observations. It regresses the average transition score of children's school peers on an indicator for whether their scores are above the cutoffs. The specification includes: (i) a linear spline in students' score distance to the cutoff, allowing the slope to vary on either side of the cutoff, and (ii) cutoff/year dummies - i.e., equation (12) with cutoff/year fixed effects. ${ }^{41}$ The results suggest that scoring above a cutoff results in a highly statistically significant increase in

score between these two month is slightly smaller but still sizable and statistically significant for most of our outcomes. We find similar results if we use a sample that is also restricted just to children born in June and July but additionally includes children born in the same months of 1991. Another alternative arises given that: (i) the gestation length varies across pregnancies, and (ii) the December 1989 legal abortions are probably more likely to have happened for mothers in their third rather than their second month of pregnancy. These factors imply that the decline in fertility after July of 1990 should not be completely instantaneous. Consistent with this, Figure 2 shows that while July of 1990 was the first month with a rapid decline in fertility, August also saw a significant further reduction. We therefore also performed some robustness checks (not reported here) restricting the sample to those born in June and August only. The results are very similar to those using the comparison of June and July.

${ }^{41}$ Our regression results are not qualitatively affected by instead using a linear, quadratic, or cubic specification for $a\left(t_{i}\right)$ in equation (10), or by excluding the cutoff fixed effects. 

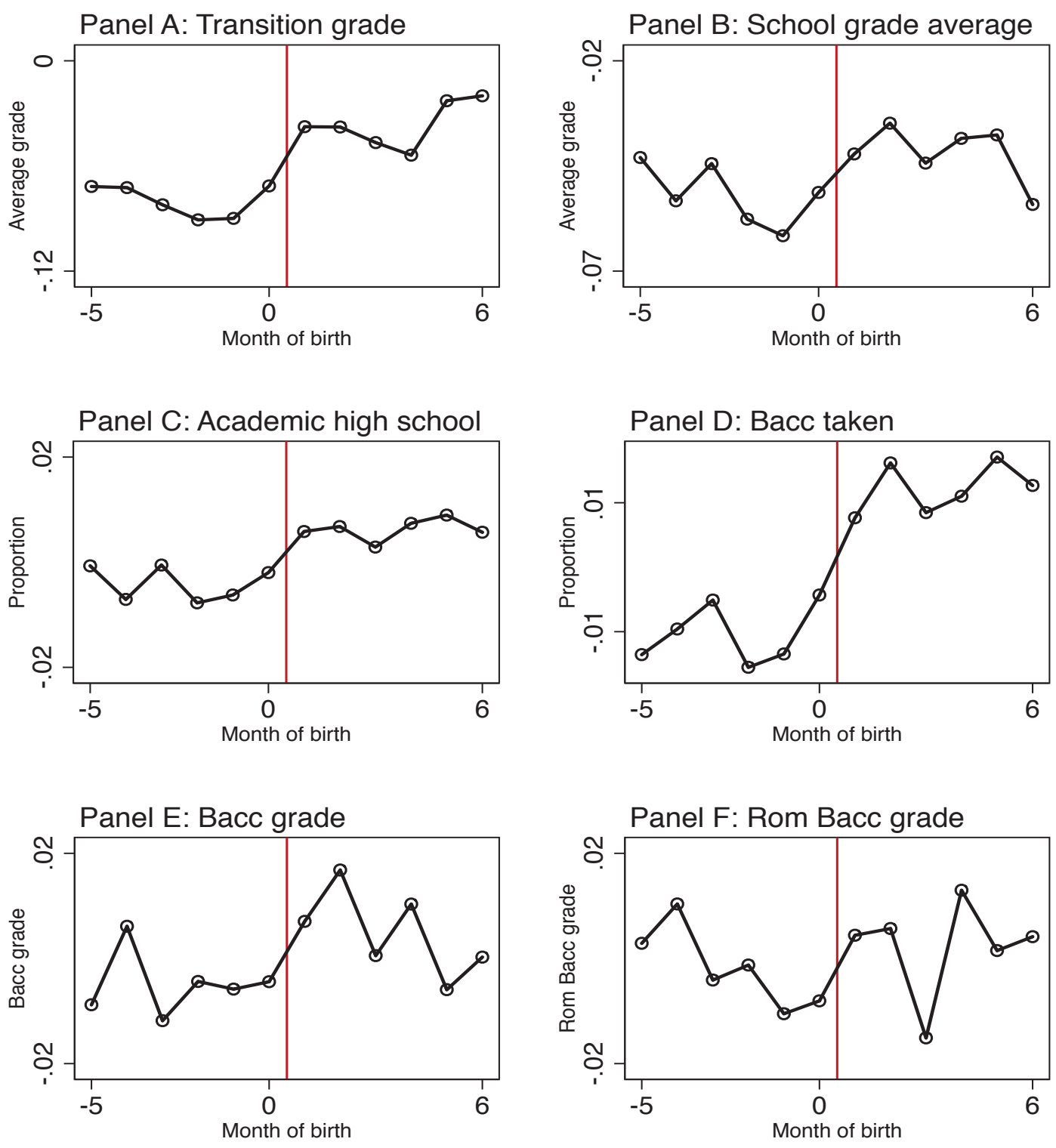

FiguRE 5. Residuals from regressions of outcomes on abortion access

Notes: All panels plot residuals from regressions similar to those in Panel D of Table 2. Specifically, they plot residuals by month of birth for children born in 1990 and present in the 2005 secondary school cohort, where the children born in 1991 and present in the 2006 cohort are included to account for month of birth effects. The fertility decrease following the introduction of greater access to abortion started with cohorts born after July of 1990 (month 0 in the above figures).

peer quality -0.1 points, equivalent to about 0.1 standard deviations in the transition score distribution.

Column (1) is our preferred specification in that it attempts to balance the goal of focusing on observations close to the cutoffs while providing enough data to yield fairly precise estimates. Several more stringent windows produce similar findings. Column (2) features one of these, a regression using the bandwidths suggested by the procedure in Imbens and 

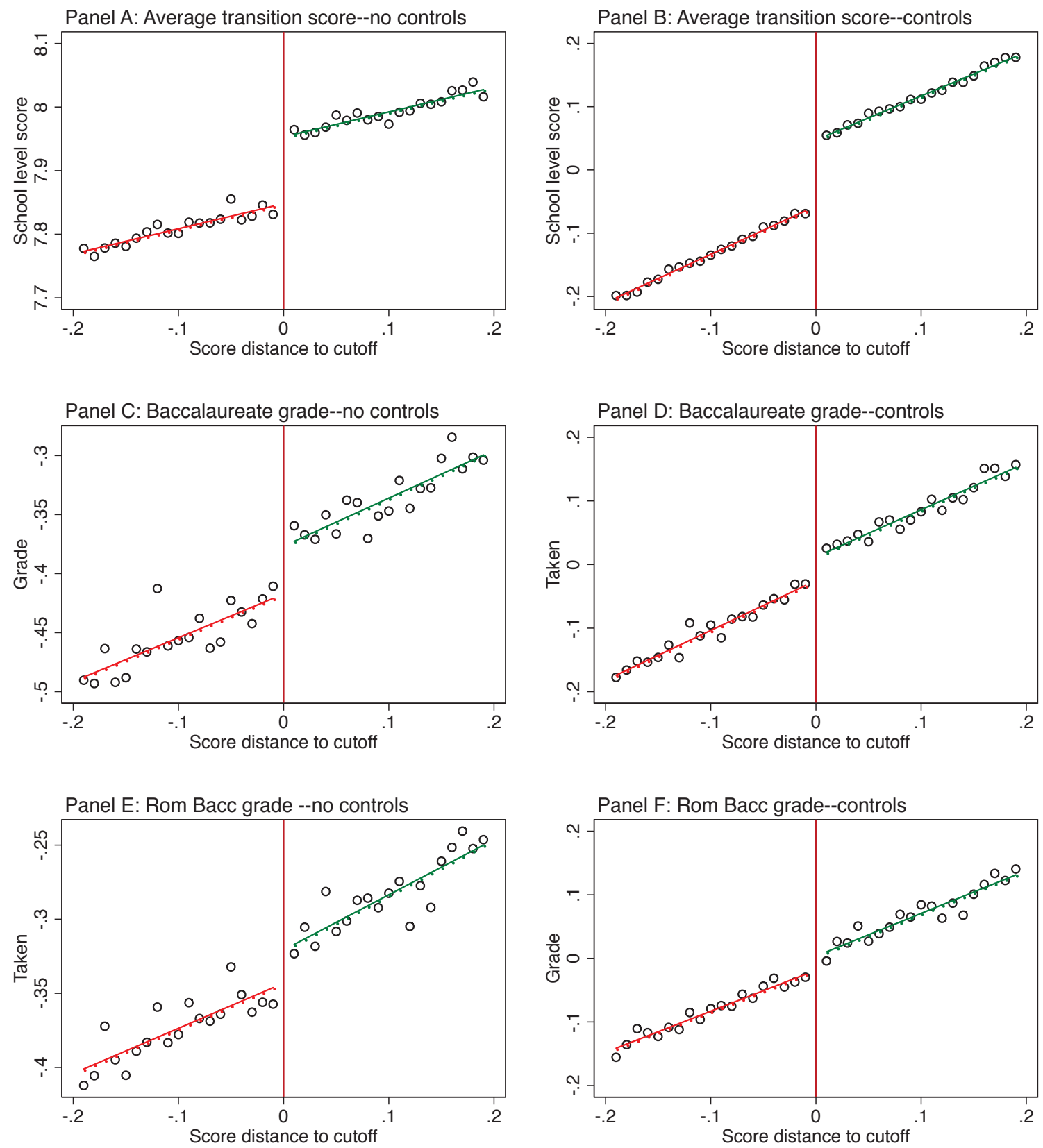

FiguRE 6 . The effect of access to a better school on educational outcomes

Notes: All panels are based on administrative data for the 2005 and 2006 admission cohorts, and restrict observations to individuals with transition scores within 0.2 points of a cutoff. The left hand side panels plot (0.01 point) transition score cell means of the dependent variable. The right hand side panels plot analogous means of residuals from a regression of the dependent variable on cutoff fixed effects. In each panel, the solid lines are fitted values of regressions of the dependent variable on a linear trend in the transition score, estimated separately on each side of the cutoff. The dependent variable in panels A and B is the average transition score of the peers students encounter at school; the dependent variable in panels $\mathrm{C}$ and $\mathrm{D}$ is an indicator for having taken the Baccalaureate exam; the dependent variable in panels $\mathrm{E}$ and $\mathrm{F}$ is the Baccalaureate grade. 
TABLE 3. The effect of access to a better school on educational outcomes

\begin{tabular}{|c|c|c|c|c|}
\hline \multirow[t]{2}{*}{ Dependent variable: } & \multicolumn{2}{|c|}{ School-level cutoffs } & \multicolumn{2}{|c|}{ Track-level cutoffs } \\
\hline & $\begin{array}{c}\text { Within } \\
1 \text { point } \\
\text { of cutoff } \\
(1)\end{array}$ & $\begin{array}{l}\text { Within } \\
\text { IK } \\
\text { bound } \\
(2) \\
\end{array}$ & $\begin{array}{c}\text { Within } \\
1 \text { point } \\
\text { of cutoff } \\
(3)\end{array}$ & $\begin{array}{l}\text { Within } \\
\text { IK } \\
\text { bound } \\
(4) \\
\end{array}$ \\
\hline \multicolumn{5}{|l|}{ Panel A: Average transition score of peers } \\
\hline Access to a better school (AccessB) & $\begin{array}{c}0.103^{* * *} \\
{[0.001]}\end{array}$ & $\begin{array}{c}0.106 * * * \\
{[0.002]}\end{array}$ & $\begin{array}{l}0.047 * * * \\
{[0.001]}\end{array}$ & $\begin{array}{c}0.050^{* * *} \\
{[0.001]}\end{array}$ \\
\hline Linear spline in score; cutoff/year dummies & Yes & Yes & Yes & Yes \\
\hline $\mathrm{N}$ & 892,225 & 562,609 & $2,369,850$ & 894,685 \\
\hline \multicolumn{5}{|l|}{ Panel B: Bacc. taken } \\
\hline Access to a better school (AccessB) & $\begin{array}{c}0.002 \\
{[0.004]}\end{array}$ & $\begin{array}{c}0.006 \\
{[0.004]}\end{array}$ & $\begin{array}{c}-0.009 * * * \\
{[0.003]}\end{array}$ & $\begin{array}{c}-0.011 * * * \\
{[0.003]}\end{array}$ \\
\hline Linear spline in score; cutoff/year dummies & Yes & Yes & Yes & Yes \\
\hline $\mathrm{N}$ & 892,225 & 778,491 & $2,369,850$ & $2,508,244$ \\
\hline \multicolumn{5}{|l|}{ Panel C: Bacc. grade } \\
\hline Access to a better school (AccessB) & $\begin{array}{l}0.0271 * * * \\
{[0.003]}\end{array}$ & $\begin{array}{c}0.0290 * * * \\
{[0.005]}\end{array}$ & $\begin{array}{c}0.009 * * * \\
{[0.002]}\end{array}$ & $\begin{array}{c}0.017 * * * \\
{[0.003]}\end{array}$ \\
\hline Linear spline in score; cutoff/year dummies & Yes & Yes & Yes & Yes \\
\hline $\mathrm{N}$ & 626,761 & 315,590 & $1,771,248$ & 689,545 \\
\hline \multicolumn{5}{|l|}{ Panel D: Romanian Bacc. grade } \\
\hline Access to a better school (AccessB) & $\begin{array}{c}0.0109 * * * \\
{[0.004]}\end{array}$ & $\begin{array}{c}0.006 \\
{[0.005]}\end{array}$ & $\begin{array}{l}0.006 * * * \\
{[0.002]}\end{array}$ & $\begin{array}{l}0.008 * * \\
{[0.003]}\end{array}$ \\
\hline $\begin{array}{l}\text { Linear spline in score; cutoff/year dummies } \\
\mathrm{N}\end{array}$ & $\begin{array}{c}\text { Yes } \\
723,055\end{array}$ & $\begin{array}{c}\text { Yes } \\
453,822 \\
\end{array}$ & $\begin{array}{c}\text { Yes } \\
1,978,326\end{array}$ & $\begin{array}{c}\text { Yes } \\
810,102 \\
\end{array}$ \\
\hline
\end{tabular}

Notes: The regressions implement specification (12). They allow for a linear spline in the running variable with a slope that can vary on each side of the cutoff. They are also clustered at the student level and include cutoff/year fixed effects. Standard errors are in brackets and all panels present reduced form specifications where the key independent variable is a dummy for whether a student's transition score is greater than or equal to the cutoff, giving him or her access to a better school. Columns (1) and (3) restrict the sample to observations within one point of the cutoff, and columns (2) and (4) to those within the Imbens and Kalyanaraman (2009) bounds. ${ }^{*} p<0.10,{ }^{* *} p<0.05,{ }^{* * *} p<0.01$.

Kalyanaraman (2009) (henceforth IK), which in our data is generally more restrictive than the 1 point band used in Column (1). ${ }^{42}$ All these samples result in similar and highly significant estimates. The "first stages" in Panel A of Table 3 are those that will be relevant for the Baccalaureate outcomes. They show that the Romanian high school admissions process makes feasible an RD-based analysis of the impact of access to a better school. ${ }^{43}$

\footnotetext{
$\overline{42}$ Specifically, we follow Lee and Lemieux (2010) and use a simple rectangular kernel. Further, we implemented the bandwidth selection procedure using the Stata ado file labeled rdob.ado, available at http://www.economics.harvard.edu/faculty/imbens/software \_imbens.

43 The RD approach additionally requires that there be no discrete changes in student characteristics that affect outcomes like Baccalaureate performance. While our administrative data do not contain such variables, our survey data suggest this condition is fulfilled. Specifically, results presented in Pop-Eleches and Urquiola (2013) shows that a number of mother, child, and household characteristics do not vary discontinuously around the cutoffs - all but one of the twenty estimates are insignificant in the sample within 1 point of the
} 
We also consider how access to a better school affects whether student take the Baccalaureate exam. Panels $\mathrm{C}$ and $\mathrm{D}$ in Figure 6 suggest little if any change in test-taking rates at the cutoffs. This is confirmed in Panel B of Table 3, which implies that having access to a better school essentially does not affect the probability of taking the Baccalaureate exam; we can rule out differences in test-taking rates of less than one-third of a percentage point. The absence of selection into taking the Baccalaureate test makes it easier to interpret the effects on Baccalaureate performance.

Turning to this, panels $\mathrm{E}$ and $\mathrm{F}$ in Figure 6 present the impact of access to a better high school on average scores, showing a discontinuous change in achievement at the cutoff. The corresponding regression results in Panel $\mathrm{C}$ of Table 3 indicate statistically significant gains equivalent to about 0.03 standard deviations in the overall score. Panel D shows that the impact on Romanian scores is also positive and significant when estimated within 1 point of the cutoff, although insignificant in the IK specification.

The bottom line is that students who score above cutoffs giving them access to better schools perform better in the high stakes Baccalaureate exam. Columns (3) and (4) in Table 3 further confirm that these conclusions hold when one considers between-track rather than between-school cutoffs. This significantly increases the number of RD-based quasiexperiments and sample sizes, and in this case all estimates of the coefficient of interest are statistically significant.

6.3. Interactions between family and school environments. We now turn to the combined RD-DD specification to examine whether access to a better school is associated with a larger or smaller effect among children who grew up in different family environments as induced by changes in access to abortion. As previewed in Section 5, the intuition surrounding our strategy, as well a useful preview of the results, can be conveyed by estimating our main access to a school effects (Table 3) for four groups of children: (1) those born during the restrictive abortion regime between January 1 and June 30 of 1990, (2) those born immediately after access to abortion increased: July 1 to December 1990, (3) those born between January 1 and June 30 of 1991, and (4) those born between July 1 and December of 1991. The children born in the first and second half of 1991 allow us to control for potential seasonality that could arise when comparing the outcomes of children born in the first and second half of 1990 .

The first two columns of Table 4 show the impact of access to a better school on taking the Baccalaureate exam for the whole sample (Panel A) and for each of these four distinct groups

cutoffs. As an additional test, Figure A.7 of the same paper shows that there is no visible jump in the density around the discontinuity; as expected, the McCrary (2008) test shows no statistically significant break. 
TABLE 4. The effect of access to a better school for different birth cohorts

\begin{tabular}{|c|c|c|c|c|c|c|}
\hline \multirow[t]{2}{*}{ Dependent variable: } & \multicolumn{2}{|c|}{ Bacc. taken } & \multicolumn{2}{|c|}{ Bacc. grade } & \multicolumn{2}{|c|}{ Romanian Bacc. grade } \\
\hline & $\begin{array}{c}\text { Within } \\
1 \text { point } \\
\text { of cutoff } \\
\text { (1) }\end{array}$ & $\begin{array}{l}\text { Within } \\
\text { IK } \\
\text { bound } \\
(2) \\
\end{array}$ & $\begin{array}{c}\text { Within } \\
1 \text { point } \\
\text { of cutoff } \\
(3)\end{array}$ & $\begin{array}{l}\text { Within } \\
\text { IK } \\
\text { bound } \\
(4) \\
\end{array}$ & $\begin{array}{c}\text { Within } \\
1 \text { point } \\
\text { of cutoff } \\
(5)\end{array}$ & $\begin{array}{c}\text { Within } \\
\text { IK } \\
\text { bound } \\
(6)\end{array}$ \\
\hline \multicolumn{7}{|l|}{ Panel A: Whole sample } \\
\hline Access to a better school $(A c c e s s B)$ & $\begin{array}{c}0.002 \\
{[0.004]}\end{array}$ & $\begin{array}{c}0.006 \\
{[0.004]}\end{array}$ & $\begin{array}{c}0.027 * * * \\
{[0.003]}\end{array}$ & $\begin{array}{c}0.029 * * * \\
{[0.005]}\end{array}$ & $\begin{array}{c}0.011^{* * *} \\
{[0.004]}\end{array}$ & $\begin{array}{c}0.006 \\
{[0.005]}\end{array}$ \\
\hline Linear spline in score; cutoff/year dummies & Yes & Yes & Yes & Yes & Yes & Yes \\
\hline $\mathrm{N}$ & 892,225 & 778,491 & 626,761 & 315,590 & 723,055 & 453,822 \\
\hline \multicolumn{7}{|l|}{ Panel B: 1990 cohort, months 1-6 } \\
\hline Access to a better school (Access $B)$ & $\begin{array}{c}0.005 \\
{[0.008]}\end{array}$ & $\begin{array}{c}0.009 \\
{[0.009]}\end{array}$ & $\begin{array}{c}0.035 * * * \\
{[0.007]}\end{array}$ & $\begin{array}{c}0.039 * * * \\
{[0.009]}\end{array}$ & $\begin{array}{c}0.027 * * * \\
{[0.007]}\end{array}$ & $\begin{array}{l}0.021^{* *} \\
{[0.009]}\end{array}$ \\
\hline Linear spline in score; cutoff/year dummies & Yes & Yes & Yes & Yes & Yes & Yes \\
\hline $\mathrm{N}$ & 276,370 & 241,177 & 192,664 & 97,360 & 218,552 & 137,385 \\
\hline \multicolumn{7}{|l|}{ Panel C: 1991 cohort, months 1-6 } \\
\hline Access to a better school $(A c c e s s B)$ & $\begin{array}{c}0.006 \\
{[0.008]}\end{array}$ & $\begin{array}{c}0.010 \\
{[0.008]}\end{array}$ & $\begin{array}{c}0.022 * * * \\
{[0.006]}\end{array}$ & $\begin{array}{c}0.028 * * * \\
{[0.010]}\end{array}$ & $\begin{array}{c}0.007 \\
{[0.007]}\end{array}$ & $\begin{array}{c}0.007 \\
{[0.009]}\end{array}$ \\
\hline Linear spline in score; cutoff/year dummies & Yes & Yes & Yes & Yes & Yes & Yes \\
\hline $\mathrm{N}$ & 224,495 & 195,720 & 155,357 & 77,951 & 183,000 & 114,866 \\
\hline \multicolumn{7}{|l|}{ Panel D: 1990 cohort, months 7-12 } \\
\hline Access to a better school (Access $B)$ & $\begin{array}{c}-0.003 \\
{[0.009]}\end{array}$ & $\begin{array}{c}0.004 \\
{[0.010]}\end{array}$ & $\begin{array}{c}0.027 * * * \\
{[0.008]}\end{array}$ & $\begin{array}{c}0.011 \\
{[0.011]}\end{array}$ & $\begin{array}{c}0.008 \\
{[0.008]}\end{array}$ & $\begin{array}{c}-0.013 \\
{[0.010]}\end{array}$ \\
\hline Linear spline in score; cutoff/year dummies & Yes & Yes & Yes & Yes & Yes & Yes \\
\hline $\mathrm{N}$ & 194,347 & 169,489 & 139,498 & 70,224 & 158,302 & 99,053 \\
\hline \multicolumn{7}{|l|}{ Panel E: 1991 cohort, months 7-12 } \\
\hline Access to a better school (AccessB) & $\begin{array}{c}-0.001 \\
{[0.008]}\end{array}$ & $\begin{array}{c}0.000 \\
{[0.009]}\end{array}$ & $\begin{array}{c}0.022 * * * \\
{[0.007]}\end{array}$ & $\begin{array}{c}0.031 * * * \\
{[0.011]}\end{array}$ & $\begin{array}{c}-0.003 \\
{[0.007]}\end{array}$ & $\begin{array}{c}0.006 \\
{[0.009]}\end{array}$ \\
\hline $\begin{array}{l}\text { Linear spline in score; cutoff/year dummies } \\
\mathrm{N}\end{array}$ & $\begin{array}{c}\text { Yes } \\
197,013\end{array}$ & $\begin{array}{c}\text { Yes } \\
172,105\end{array}$ & $\begin{array}{c}\text { Yes } \\
139,242\end{array}$ & $\begin{array}{c}\text { Yes } \\
70,055\end{array}$ & $\begin{array}{c}\text { Yes } \\
163,201\end{array}$ & $\begin{array}{c}\text { Yes } \\
102,518\end{array}$ \\
\hline
\end{tabular}

Notes: The regressions implement the specification in Table 3. Panel A applies this specification to the whole sample, thus replicating some results in that table. Panels B-E break the sample into four subgroups covering four six-month periods in the two birth years that make up the full sample. Specifically, Panel B refers to children born between January and June (inclusive) of 1990, and Panel C covers the same months of 1991. Panel D refers to the children born between July and December (inclusive) of 1990, and panel E covers the same months of $1991 .{ }^{*} p<0.10,{ }^{* *} p<0.05,{ }^{* * *} p<0.01$.

(panels, B, C, D, and E). The estimates across most specifications are small and insignificant. This is not surprising given that above we found few effects for this educational outcome.

The final four columns of Table 4 present analogous impacts on the overall Baccalaureate grade (columns 3-4) and the Romanian Baccalaureate grade (columns 5-6). The results in column (3) are striking. First, they show consistent positive and statistically significant effects of having access to a better school, although the estimates for 1991 are somewhat smaller than those for 1990. Second, the largest effects are observed for the group born before July of 1990; in other words the later intervention - access to a better school - seems to have had the largest effect upon the children who did not benefit from parental access to abortion and therefore had lower achievement upon entering high school. Third, these 
four coefficients can be used to calculate a difference-in-differences estimate of the effect of having access to a better school among children who were born under increased access to abortion. This is very much in the spirit of equation (14) and of our interacted specification (15). A back of the envelope calculation using the sample within 1 point of the cutoff implies a difference-in-differences estimate of -0.008 .

The results for the Romanian Baccalaureate grade (column 5, Table 4) are even more striking; the only significant effects from having access to a better school are observed for the cohort born during the restrictive abortion regime. Again, if anything, the interaction between access to abortion and access to a better school is negative for this outcome.

We now turn to our full interacted RD-DD framework (equation 15). In Table 5 our preferred specification (Panel C) uses quadratic trends in month of birth. As before, we also consider alternative specifications that only include the 2005 cohort (Panel A) or where we use an indicator for being born in the first six months of the year (Panel B) and a set of calendar month of birth dummies (Panel D) to model time trends. In columns (1) and (2) the outcome of interest is an indicator for taking the Baccalaureate exam; in columns (3) and (4) it is performance in the exam overall; in columns (5) and (6) it is performance in the Romanian language component. As before, for each of the three outcome variables we use two samples: one restricted to individuals within one point of the cutoff, and one restricted to those withing the IK bandwidth.

Table 5 thus describes the differential impact associated with access to a better school for children born before and after the access to abortion increased. To begin with, one observes a pattern of results that replicates the main effects shown above for each source of variation. Specifically, the coefficient for being above a school cutoff $\left(\right.$ Access $\left.B_{i}\right)$ is small and statistically insignificant for taking the Baccalaureate exam, and positive and significant in our preferred specification (Panel C, column 3) for the Baccalaureate grade. The key result refers to the interaction of access to abortion $\left(\right.$ Access $\left._{i}\right)$ and access to a better school $\left(\right.$ Access $\left._{i}\right)$ in Panel C of Table 5. The interaction coefficients in columns 3-6 are generally negative and small, though two are statistically significant. This suggest that, at least in our setting, there is little evidence for a positive interaction between shocks to family and school environments.

We include two further tables with robustness checks in the Appendix. First, Table 8 replicates Table 5 using the between-track rather than between school cutoffs. Second, Table 9 does the same for the survey subsample. The conclusions that emerge are similar, although the coefficients in the survey sample are not surprisingly insignificant given the much lower sample sizes. 
TABLE 5. The interaction of access to abortion and to a better school

\begin{tabular}{|c|c|c|c|c|c|c|}
\hline & \multicolumn{2}{|c|}{ Bacc. taken } & \multicolumn{2}{|c|}{ Bacc. grade } & \multicolumn{2}{|c|}{ Romanian Bacc. grade } \\
\hline & $\begin{array}{c}\text { Within } \\
1 \text { point } \\
\text { of cutoff } \\
\text { (1) }\end{array}$ & $\begin{array}{l}\text { Within } \\
\text { IK } \\
\text { bound } \\
(2) \\
\end{array}$ & $\begin{array}{c}\text { Within } \\
1 \text { point } \\
\text { of cutoff } \\
(3)\end{array}$ & $\begin{array}{l}\text { Within } \\
\text { IK } \\
\text { bound } \\
(4) \\
\end{array}$ & $\begin{array}{c}\text { Within } \\
1 \text { point } \\
\text { of cutoff } \\
(5)\end{array}$ & $\begin{array}{l}\text { Within } \\
\text { IK } \\
\text { bound } \\
(6)\end{array}$ \\
\hline \multicolumn{7}{|l|}{ Panel A: 2005 cohort } \\
\hline $\begin{array}{l}\text { Access to a better school } \\
(\text { AccessB })\end{array}$ & $\begin{array}{c}0.002 \\
{[0.023]}\end{array}$ & $\begin{array}{c}0.009 \\
{[0.025]}\end{array}$ & $\begin{array}{c}0.031 \\
{[0.019]}\end{array}$ & $\begin{array}{c}0.010 \\
{[0.026]}\end{array}$ & $\begin{array}{c}0.006 \\
{[0.019]}\end{array}$ & $\begin{array}{c}0.011 \\
{[0.024]}\end{array}$ \\
\hline Abortion access $(A c c e s s A)$ & $\begin{array}{c}0.016 \\
{[0.025]}\end{array}$ & $\begin{array}{c}0.019 \\
{[0.026]}\end{array}$ & $\begin{array}{c}0.010 \\
{[0.022]}\end{array}$ & $\begin{array}{c}0.017 \\
{[0.026]}\end{array}$ & $\begin{array}{c}0.013 \\
{[0.021]}\end{array}$ & $\begin{array}{c}0.014 \\
{[0.024]}\end{array}$ \\
\hline Access $B *$ Access $A$ & $\begin{array}{c}0.0301 \\
{[0.0228]}\end{array}$ & $\begin{array}{c}0.0314 \\
{[0.0252]}\end{array}$ & $\begin{array}{c}-0.018 \\
{[0.0202]}\end{array}$ & $\begin{array}{l}-0.050^{*} \\
{[0.0278]}\end{array}$ & $\begin{array}{c}-0.018 \\
{[0.0200]}\end{array}$ & $\begin{array}{c}-0.017 \\
{[0.0255]}\end{array}$ \\
\hline Monthly trend & $\mathrm{Y}$ & $\mathrm{Y}$ & $\mathrm{Y}$ & $\mathrm{Y}$ & $\mathrm{Y}$ & $\mathrm{Y}$ \\
\hline Calendar month dummies & $\mathrm{N}$ & $\mathrm{N}$ & $\mathrm{N}$ & $\mathrm{N}$ & $\mathrm{N}$ & $\mathrm{N}$ \\
\hline Cohort dummy & $\mathrm{N}$ & $\mathrm{N}$ & $\mathrm{N}$ & $\mathrm{N}$ & $\mathrm{N}$ & $\mathrm{N}$ \\
\hline $\mathrm{N}$ & 470,717 & 410,666 & 332,162 & 167,584 & 376,854 & 236,438 \\
\hline \multicolumn{7}{|c|}{ Panel B: 2005 and 2006 cohorts } \\
\hline $\begin{array}{l}\text { Access to a better school } \\
(\text { Access } B)\end{array}$ & $\begin{array}{l}-0.002 \\
{[0.014]}\end{array}$ & $\begin{array}{l}-0.001 \\
{[0.015]}\end{array}$ & $\begin{array}{c}0.035^{* * *} \\
{[0.012]}\end{array}$ & $\begin{array}{l}0.043 * * \\
{[0.017]}\end{array}$ & $\begin{array}{c}0.017 \\
{[0.012]}\end{array}$ & $\begin{array}{c}0.021 \\
{[0.015]}\end{array}$ \\
\hline Abortion access (Access $A$ ) & $\begin{array}{c}0.021 \\
{[0.019]}\end{array}$ & $\begin{array}{c}0.013 \\
{[0.019]}\end{array}$ & $\begin{array}{c}0.010 \\
{[0.016]}\end{array}$ & $\begin{array}{c}0.012 \\
{[0.019]}\end{array}$ & $\begin{array}{l}-0.004 \\
{[0.016]}\end{array}$ & $\begin{array}{c}0.013 \\
{[0.018]}\end{array}$ \\
\hline Access $B * A \operatorname{ccess} A$ & $\begin{array}{l}-0.001 \\
{[0.017]}\end{array}$ & $\begin{array}{c}0.005 \\
{[0.018]}\end{array}$ & $\begin{array}{l}-0.007 \\
{[0.014]}\end{array}$ & $\begin{array}{l}-0.031 \\
{[0.020]}\end{array}$ & $\begin{array}{l}-0.008 \\
{[0.014]}\end{array}$ & $\begin{array}{l}-0.033^{*} \\
{[0.018]}\end{array}$ \\
\hline Monthly trend & $\mathrm{N}$ & $\mathrm{N}$ & $\mathrm{N}$ & $\mathrm{N}$ & $\mathrm{N}$ & $\mathrm{N}$ \\
\hline Calendar month dummies & $\mathrm{N}$ & $\mathrm{N}$ & $\mathrm{N}$ & $\mathrm{N}$ & $\mathrm{N}$ & $\mathrm{N}$ \\
\hline Cohort dummy & $\mathrm{Y}$ & $\mathrm{Y}$ & $\mathrm{Y}$ & $\mathrm{Y}$ & $\mathrm{Y}$ & $\mathrm{Y}$ \\
\hline $\mathrm{N}$ & 892,225 & 778,491 & 626,761 & 315,590 & 723,055 & 453,822 \\
\hline \multicolumn{7}{|c|}{ Panel C: 2005 and 2006 cohorts } \\
\hline $\begin{array}{l}\text { Access to a better school } \\
(\text { AccessB })\end{array}$ & $\begin{array}{c}0.006 \\
{[0.016]}\end{array}$ & $\begin{array}{c}0.012 \\
{[0.017]}\end{array}$ & $\begin{array}{l}0.026 * * \\
{[0.013]}\end{array}$ & $\begin{array}{c}0.012 \\
{[0.019]}\end{array}$ & $\begin{array}{c}0.013 \\
{[0.013]}\end{array}$ & $\begin{array}{c}0.002 \\
{[0.017]}\end{array}$ \\
\hline Abortion access (Access $A)$ & $\begin{array}{c}0.024 \\
{[0.017]}\end{array}$ & $\begin{array}{c}0.022 \\
{[0.017]}\end{array}$ & $\begin{array}{c}0.017 \\
{[0.014]}\end{array}$ & $\begin{array}{c}0.019 \\
{[0.017]}\end{array}$ & $\begin{array}{c}0.006 \\
{[0.014]}\end{array}$ & $\begin{array}{c}0.021 \\
{[0.016]}\end{array}$ \\
\hline Access $B *$ Access $A$ & $\begin{array}{c}0.002 \\
{[0.015]}\end{array}$ & $\begin{array}{c}0.005 \\
{[0.016]}\end{array}$ & $\begin{array}{l}-0.010 \\
{[0.013]}\end{array}$ & $\begin{array}{c}-0.037 * * \\
{[0.018]}\end{array}$ & $\begin{array}{l}-0.017 \\
{[0.013]}\end{array}$ & $\begin{array}{c}-0.037 * * \\
{[0.017]}\end{array}$ \\
\hline Monthly trend & $\mathrm{Y}$ & $\mathrm{Y}$ & $\mathrm{Y}$ & $\mathrm{Y}$ & $\mathrm{Y}$ & $\mathrm{Y}$ \\
\hline Calendar month dummies & $\mathrm{N}$ & $\mathrm{N}$ & $\mathrm{N}$ & $\mathrm{N}$ & $\mathrm{N}$ & $\mathrm{N}$ \\
\hline Cohort dummy & $\mathrm{Y}$ & $\mathrm{Y}$ & $\mathrm{Y}$ & $\mathrm{Y}$ & $\mathrm{Y}$ & $\mathrm{Y}$ \\
\hline $\mathrm{N}$ & 892,225 & 778,491 & 626,761 & 315,590 & 723,055 & 453,822 \\
\hline Panel D: 2005 and $2006 \mathrm{co}$ & & & & & & \\
\hline $\begin{array}{l}\text { Access to a better school } \\
(\text { Access } B)\end{array}$ & $\begin{array}{l}-0.016 \\
{[0.024]}\end{array}$ & $\begin{array}{l}-0.014 \\
{[0.026]}\end{array}$ & $\begin{array}{c}0.054 * * * \\
{[0.021]}\end{array}$ & $\begin{array}{c}0.049 \\
{[0.030]}\end{array}$ & $\begin{array}{c}0.029 \\
{[0.021]}\end{array}$ & $\begin{array}{c}0.020 \\
{[0.027]}\end{array}$ \\
\hline Abortion access (Access $A$ ) & $\begin{array}{c}0.020 \\
{[0.019]}\end{array}$ & $\begin{array}{c}0.013 \\
{[0.019]}\end{array}$ & $\begin{array}{c}0.010 \\
{[0.016]}\end{array}$ & $\begin{array}{c}0.012 \\
{[0.019]}\end{array}$ & $\begin{array}{c}-0.005 \\
{[0.016]}\end{array}$ & $\begin{array}{c}0.013 \\
{[0.018]}\end{array}$ \\
\hline$A c c e s s B^{*}$ Access $A$ & $\begin{array}{c}0.000 \\
{[0.017]}\end{array}$ & $\begin{array}{c}0.005 \\
{[0.018]}\end{array}$ & $\begin{array}{c}-0.008 \\
{[0.014]}\end{array}$ & $\begin{array}{c}-0.032 \\
{[0.020]}\end{array}$ & $\begin{array}{c}-0.008 \\
{[0.014]}\end{array}$ & $\begin{array}{l}-0.034 * \\
{[0.018]}\end{array}$ \\
\hline Monthly trend & $\mathrm{N}$ & $\mathrm{N}$ & $\mathrm{N}$ & $\mathrm{N}$ & $\mathrm{N}$ & $\mathrm{N}$ \\
\hline Calendar month dummies & $\mathrm{Y}$ & $\mathrm{Y}$ & $\mathrm{Y}$ & $\mathrm{Y}$ & $\mathrm{Y}$ & $\mathrm{Y}$ \\
\hline Cohort dummy & $\mathrm{Y}$ & $\mathrm{Y}$ & $\mathrm{Y}$ & $\mathrm{Y}$ & $\mathrm{Y}$ & $\mathrm{Y}$ \\
\hline $\mathrm{N}$ & 892,225 & 778,491 & 626,761 & 315,590 & 723,055 & 453,822 \\
\hline
\end{tabular}

Notes: These regressions implement specification (15). They are clustered at the student level and include cutoff fixed effects, where the cutoffs are those between schools. Standard errors are in brackets. All panels present reduced form specifications where the key independent variable is a dummy for the interaction of access to abortion and access to a better school. ${ }^{*} p<0.10,{ }^{* *} p<0.05,{ }^{* * *} p<0.01$. 
6.4. Behavioral responses. The interactions between family and school environments estimated in the previous section may reflect the presence of dynamic complementarities in the technology of human capital formation, but they may also capture behavioral responses on the part of parents and children (and other agents such as teachers). We explore such responses using our survey data, focusing on parental and student effort around homework as well as parental decisions on whether to hire a tutor.

Table 6 presents the results, using the specifications featured in Table 5. The interactions between the impact of increased access to abortion $\left(\right.$ Access $\left._{i}\right)$ and access to a better school $\left(\right.$ Access $\left._{i}\right)$ on whether parents help children with homework are consistently negative, albeit insignificant. This would suggest that children born after there was greater access to abortion receive less parental help with homework when they have access to a better school. Similarly, we observe negative and significant interactions on children's reports of doing homework. ${ }^{44}$ The effects surrounding whether parents hire a tutor are less conclusive.

Taken together these results suggest that parental and student behavior may partially undo dynamic complementarities between family and school environments, at least in the Romanian setting. We cannot make this statement conclusively due to the lack of statistical power and because we only have a limited set of outcomes. Nevertheless, the pattern does suggest that our reduced-form estimates are not necessarily inconsistent with the existence of dynamic complementarities in the technology of human capital formation.

6.5. Robustness checks and interpretation issues. In this final section we address three sets of issues that arise given the sources of variation we use: crowding, composition effects, and possible biases from the distribution of children across cutoffs.

6.5.1. Crowding. The first issue is simply that our results might be driven by changes in crowding, since smaller cohorts were born in the months after access to abortion increased. The children born in July, 1990 and later therefore on average encountered less crowding in many settings. For example, in some cases they might have experienced smaller class sizes in elementary school. Any differential performance on their part might therefore reflect that they enjoyed more inputs on average. As stated this issue is mitigated in our setting due to the timing of the collapse of communism. Specifically, the children born just before and just after the decline in fertility - those our DD empirical strategy focuses on - entered school in the same academic year. They thus likely encountered similar crowding conditions.

Nevertheless, it is possible that the larger cohorts born during the period of the abortion ban faced larger crowding in the medical system during pre and postnatal care, and this might

44 The same patterns emerge if we examine parental reports on whether children exert effort doing homework. 
TABLE 6. Behavioral responses

\begin{tabular}{|c|c|c|c|c|c|c|}
\hline & \multicolumn{2}{|c|}{$\begin{array}{c}\text { Parent helps } \\
\text { with homework }\end{array}$} & \multicolumn{2}{|c|}{$\begin{array}{c}\text { Child reports doing } \\
\text { homework }\end{array}$} & \multicolumn{2}{|c|}{$\begin{array}{l}\text { Parent reports } \\
\text { paying for tutor }\end{array}$} \\
\hline & $\begin{array}{c}\text { Within } \\
1 \text { point } \\
\text { of cutoff } \\
\text { (1) }\end{array}$ & $\begin{array}{l}\text { Within } \\
\text { IK } \\
\text { bound } \\
(2)\end{array}$ & $\begin{array}{c}\text { Within } \\
1 \text { point } \\
\text { of cutoff } \\
\text { (3) }\end{array}$ & $\begin{array}{l}\text { Within } \\
\text { IK } \\
\text { bound } \\
(4)\end{array}$ & $\begin{array}{c}\text { Within } \\
1 \text { point } \\
\text { of cutoff } \\
\text { (5) }\end{array}$ & $\begin{array}{l}\text { Within } \\
\text { IK } \\
\text { bound } \\
(6)\end{array}$ \\
\hline \multicolumn{7}{|l|}{ Panel A: 2005 cohort } \\
\hline Access to a better school (AccessB) & $\begin{array}{c}0.060 \\
{[0.116]}\end{array}$ & $\begin{array}{c}0.007 \\
{[0.102]}\end{array}$ & $\begin{array}{l}-0.171 \\
{[0.157]}\end{array}$ & $\begin{array}{l}-0.090 \\
{[0.137]}\end{array}$ & $\begin{array}{c}0.041 \\
{[0.141]}\end{array}$ & $\begin{array}{c}0.029 \\
{[0.142]}\end{array}$ \\
\hline Abortion access $($ Access $A)$ & $\begin{array}{l}0.1316 \\
{[0.104]}\end{array}$ & $\begin{array}{l}0.201 * * \\
{[0.099]}\end{array}$ & $\begin{array}{l}0.273 * * \\
{[0.136]}\end{array}$ & $\begin{array}{c}0.243^{*} \\
{[0.125]}\end{array}$ & $\begin{array}{l}-0.146 \\
{[0.114]}\end{array}$ & $\begin{array}{l}-0.146 \\
{[0.114]}\end{array}$ \\
\hline Access $B^{*}$ Access $A$ & $\begin{array}{l}-0.1601 \\
{[0.131]}\end{array}$ & $\begin{array}{l}-0.191 \\
{[0.120]}\end{array}$ & $\begin{array}{c}-0.370 * * \\
{[0.173]}\end{array}$ & $\begin{array}{c}-0.366^{* *} \\
{[0.149]}\end{array}$ & $\begin{array}{c}0.063 \\
{[0.154]}\end{array}$ & $\begin{array}{c}0.064 \\
{[0.154]}\end{array}$ \\
\hline Monthly trend & $\mathrm{Y}$ & $\mathrm{Y}$ & $\mathrm{Y}$ & $\mathrm{Y}$ & $\mathrm{Y}$ & $\mathrm{Y}$ \\
\hline Calendar month dummies & $\mathrm{N}$ & $\mathrm{N}$ & $\mathrm{N}$ & $\mathrm{N}$ & $\mathrm{N}$ & $\mathrm{N}$ \\
\hline Cohort dummy & $\mathrm{N}$ & $\mathrm{N}$ & $\mathrm{N}$ & $\mathrm{N}$ & $\mathrm{N}$ & $\mathrm{N}$ \\
\hline $\mathrm{N}$ & 1,827 & 2,426 & 1,843 & 2,635 & 1,840 & 1,830 \\
\hline \multicolumn{7}{|l|}{ Panel B: 2005 and 2006 cohorts } \\
\hline Access to a better school (Access $B)$ & $\begin{array}{c}0.092 \\
{[0.086]}\end{array}$ & $\begin{array}{c}0.092 \\
{[0.073]}\end{array}$ & $\begin{array}{c}0.137 \\
{[0.107]}\end{array}$ & $\begin{array}{c}0.132 \\
{[0.103]}\end{array}$ & $\begin{array}{c}0.066 \\
{[0.084]}\end{array}$ & $\begin{array}{c}0.072 \\
{[0.081]}\end{array}$ \\
\hline Abortion access (Access $A)$ & $\begin{array}{c}0.129 \\
{[0.080]}\end{array}$ & $\begin{array}{l}0.120^{*} \\
{[0.072]}\end{array}$ & $\begin{array}{c}0.143 \\
{[0.099]}\end{array}$ & $\begin{array}{l}0.165 * \\
{[0.096]}\end{array}$ & $\begin{array}{c}0.000 \\
{[0.076]}\end{array}$ & $\begin{array}{l}-0.003 \\
{[0.075]}\end{array}$ \\
\hline Access $B^{*}$ Access $A$ & $\begin{array}{l}-0.136 \\
{[0.101]}\end{array}$ & $\begin{array}{c}-0.104 \\
{[0.088]}\end{array}$ & $\begin{array}{l}-0.127 \\
{[0.127]}\end{array}$ & $\begin{array}{l}-0.143 \\
{[0.122]}\end{array}$ & $\begin{array}{l}-0.030 \\
{[0.104]}\end{array}$ & $\begin{array}{l}-0.037 \\
{[0.101]}\end{array}$ \\
\hline Monthly trend & $\mathrm{N}$ & $\mathrm{N}$ & $\mathrm{N}$ & $\mathrm{N}$ & $\mathrm{N}$ & $\mathrm{N}$ \\
\hline Calendar month dummies & $\mathrm{N}$ & $\mathrm{N}$ & $\mathrm{N}$ & $\mathrm{N}$ & $\mathrm{N}$ & $\mathrm{N}$ \\
\hline Cohort dummy & $\mathrm{Y}$ & $\mathrm{Y}$ & $\mathrm{Y}$ & $\mathrm{Y}$ & $\mathrm{Y}$ & $\mathrm{Y}$ \\
\hline $\mathrm{N}$ & 3,512 & 4,702 & 3,548 & 3,873 & 3,526 & 3,724 \\
\hline \multicolumn{7}{|l|}{ Panel C: 2005 and 2006 cohorts } \\
\hline Access to a better school (AccessB) & $\begin{array}{c}0.048 \\
{[0.089]}\end{array}$ & $\begin{array}{c}0.007 \\
{[0.077]}\end{array}$ & $\begin{array}{l}-0.058 \\
{[0.116]}\end{array}$ & $\begin{array}{l}-0.019 \\
{[0.113]}\end{array}$ & $\begin{array}{c}0.124 \\
{[0.094]}\end{array}$ & $\begin{array}{c}0.118 \\
{[0.092]}\end{array}$ \\
\hline Abortion access (Access $A)$ & $\begin{array}{c}0.077 \\
{[0.070]}\end{array}$ & $\begin{array}{l}0.108^{*} \\
{[0.065]}\end{array}$ & $\begin{array}{l}0.191 * * \\
{[0.089]}\end{array}$ & $\begin{array}{l}0.206 * * \\
{[0.086]}\end{array}$ & $\begin{array}{l}-0.059 \\
{[0.070]}\end{array}$ & $\begin{array}{l}-0.069 \\
{[0.069]}\end{array}$ \\
\hline Access $B^{*}$ Access $A$ & $\begin{array}{l}-0.068 \\
{[0.089]}\end{array}$ & $\begin{array}{c}-0.085 \\
{[0.079]}\end{array}$ & $\begin{array}{l}-0.194 * \\
{[0.114]}\end{array}$ & $\begin{array}{c}-0.220 * * \\
{[0.109]}\end{array}$ & $\begin{array}{l}0.0259 \\
{[0.096]}\end{array}$ & $\begin{array}{l}0.0334 \\
{[0.094]}\end{array}$ \\
\hline Monthly trend & $\mathrm{Y}$ & $\mathrm{Y}$ & $\mathrm{Y}$ & $\mathrm{Y}$ & $\mathrm{Y}$ & $\mathrm{Y}$ \\
\hline Calendar month dummies & $\mathrm{N}$ & $\mathrm{N}$ & $\mathrm{N}$ & $\mathrm{N}$ & $\mathrm{N}$ & $\mathrm{N}$ \\
\hline Cohort dummy & $\mathrm{Y}$ & $\mathrm{Y}$ & $\mathrm{Y}$ & $\mathrm{Y}$ & $\mathrm{Y}$ & $\mathrm{Y}$ \\
\hline $\mathrm{N}$ & 3,512 & 4,702 & 3,548 & 3,873 & 3,526 & 3,724 \\
\hline \multicolumn{7}{|l|}{ Panel D: 2005 and 2006 cohorts } \\
\hline Access to a better school (Access $B)$ & $\begin{array}{c}0.074 \\
{[0.135]}\end{array}$ & $\begin{array}{c}0.131 \\
{[0.120]}\end{array}$ & $\begin{array}{c}0.423 * * \\
{[0.176]}\end{array}$ & $\begin{array}{c}0.385^{* *} \\
{[0.169]}\end{array}$ & $\begin{array}{c}0.079 \\
{[0.131]}\end{array}$ & $\begin{array}{c}0.062 \\
{[0.128]}\end{array}$ \\
\hline Abortion access (Access $A)$ & $\begin{array}{c}0.122 \\
{[0.080]}\end{array}$ & $\begin{array}{c}0.114 \\
{[0.073]}\end{array}$ & $\begin{array}{c}0.152 \\
{[0.101]}\end{array}$ & $\begin{array}{l}0.175^{*} \\
{[0.098]}\end{array}$ & $\begin{array}{l}-0.011 \\
{[0.077]}\end{array}$ & $\begin{array}{l}-0.008 \\
{[0.075]}\end{array}$ \\
\hline Access $B^{*}$ Access $A$ & $\begin{array}{l}-0.125 \\
{[0.102]}\end{array}$ & $\begin{array}{c}-0.093 \\
{[0.089]}\end{array}$ & $\begin{array}{c}-0.152 \\
{[0.129]}\end{array}$ & $\begin{array}{l}-0.170 \\
{[0.124]}\end{array}$ & $\begin{array}{l}-0.025 \\
{[0.105]}\end{array}$ & $\begin{array}{l}-0.039 \\
{[0.102]}\end{array}$ \\
\hline Monthly trend & $\mathrm{N}$ & $\mathrm{N}$ & $\mathrm{N}$ & $\mathrm{N}$ & $\mathrm{N}$ & $\mathrm{N}$ \\
\hline Calendar month dummies & $\mathrm{Y}$ & $\mathrm{Y}$ & $\mathrm{Y}$ & $\mathrm{Y}$ & $\mathrm{Y}$ & $\mathrm{Y}$ \\
\hline Cohort dummy & $\mathrm{Y}$ & $\mathrm{Y}$ & $\mathrm{Y}$ & $\mathrm{Y}$ & $\mathrm{Y}$ & $\mathrm{Y}$ \\
\hline $\mathrm{N}$ & 3,512 & 4,702 & 3,548 & 3,873 & 3,526 & 3,724 \\
\hline
\end{tabular}

Notes: These regressions implement specification (15). They are clustered at the student level and include cutoff fixed effects, where the cutoffs are those between schools. Standard errors are in brackets. All panels present reduced form specifications where the key independent variable is a dummy for the interaction of access to abortion and access to a better school. ${ }^{*} p<0.10,{ }^{* *} p<0.05,{ }^{* * *} p<0.01$. 
have affected their outcomes later in life. While this particular mechanism is strictly speaking not a shock to the family environment, we interpret it broadly to also be an exogenous shock during early childhood. We thus use it in the spirit of understanding possible interactions between early childhood environments and later educational shocks.

6.5.2. Composition effects. Our results might be driven by composition effects if the abortion policy led to changes in the socioeconomic characteristics of women who carry pregnancies to term. If this were the only change induced by the abortion policy, our analysis would reduce to exploring the heterogeneity of the effects of school quality by parental characteristics rather than the dynamic complementarities between early parental investments and later school investments.

We now consider the evidence for such composition effects. In Table 10 (in the Appendix) Panel A presents markers of mothers' socio-economic status that are likely to affect children's academic performance; these include mothers' educational attainment and whether they were born in an urban area. The signs of the coefficients on educational attainment (columns 13) suggest that the mothers of children born after access to abortion increased were more educated, and they were less likely to have been born in urban areas (column 4). However, none of these coefficients are statistically significant.

Panel B of Table 10 complements this analysis by considering the effect of abortion access on markers often related to the prevalence of "unwanted" children. For instance, all else equal, women who are divorced as opposed to married, and older as opposed to younger, may wish to have fewer children. Column (1) shows that increased access to abortion led to a 0.7 percent increase in the probability that mothers were married (column 1), although there is little evidence of an impact on the likelihood that they were divorced (column 2). Not surprisingly, column (3) indicates a reduction in the number of children after liberalization. This, along with the large decrease in fertility after July of 1990 (Figure 2), provides the most direct evidence that many children born under the abortion ban were not wanted by their parents. However, the changes in the patterns of age at birth and life-cycle fertility provide additional support for this claim. Column (4) shows that the mothers of children born after access to abortion increased were also younger by approximately 0.25 years. This suggests that on average older women responded more to the increased availability of abortion, presumably because they were more likely to have reached or exceeded their ideal family size under the restrictive regime. This is also consistent with evidence that greater access to abortion led to a decrease in each mother's total fertility.

Thus, Table 10 suggests that changes in the composition of births are unlikely to fully account for the results we found above. We explore this more directly by adding controls 
to our previous specifications. Table 11 (in the appendix) uses the administrative data and adds a current poverty status indicator, ${ }^{45}$ while Table 12 (also in the appendix) uses the survey data and includes an indicator for whether mothers have higher education. Both tables have a similar structure. For conciseness, we focus on our preferred specification - the one that includes quadratic trends in month of birth to control for seasonality. In each case, Panel A simply replicates our main results showing the combined RD-DD specifications that include interactions between access to abortion and access to a better school.

Panel B of each table estimates the main effects and the interaction between either poverty status or mother's education and the effect of having access to a better school, including the controls. In Table 11, the interactions in Panel B show that children who are not poor are significantly more likely to take the Baccalaureate exam and to score higher, but there is no indication that the effect of having access to a better school is different for poor and non-poor students. In Table 12, Panel B shows that children with more educated mothers do score higher on the Baccalaureate exam, although this is insignificant for the Romanian component and only marginally significantly overall. Finally, Panel C of each table includes both interactions between access to abortion and to a better school, as well as a further interaction between either poverty status or mothers' education and the indicator for having access to a better school. The key interactions between access to abortion and to a better school are not much affected by the inclusion of these controls for background characteristics. This leads us to conclude that composition is not driving our main results and that differential investments in the family environment are likely to be playing a central role.

6.5.3. Distribution of children across cutoffs. If access to abortion affects children's transition scores, as our results suggest, it may also affect their ability to gain admission to better schools. This raises the possibility that children born before and after access to abortion increased may be differentially distributed across the cutoffs that determine access to better schools, and this could be a source of differential improvements in Baccalaureate scores. For example, suppose that children born after the abortion ban was repealed were systematically more likely to end up at cutoffs at which the benefit of going to a better school was smaller; this could explain why we do not find evidence of dynamic complementarities.

Figure 8 (in the Appendix) presents evidence suggesting this is not the case. First, we estimate the interaction between access to abortion $\left(\right.$ Access $\left._{i}\right)$ and access to a better school $\left(\right.$ Access $\left.B_{i}\right)$ separately by tercile of the school quality distribution (parametrized by the

$\overline{45}$ This measure of poverty is used by schools to determine eligibility for a scholarship program, and has the advantage of allowing us to maintain high sample sizes. However, there may be concern that this variable is endogenous if it is itself affected by access to abortion. 
transition scores of the cutoff for entry to each school). We plot these estimates as vertical bars for each of the four specifications associated with our abortion models. ${ }^{46}$ The interaction effects are negative in each tercile and for almost every specification. Thus, it does not appear that our main findings are driven by schools in certain parts of the quality distribution. Second, we estimate the main effects of access to a better school (Access $B_{i}$ ) separately by tercile of the school quality distribution for children who were born in 1990 either before or after access to abortion increased. These are plotted as the dotted and solid lines respectively. The fact that both of these lines slope upwards suggests that the effect of access to a better school is, if anything, increasing in school quality. Thus, it does not appear that our findings can be explained by the fact that children born after access to abortion increased were systematically more likely to end up at cutoffs at which the benefit of going to a better school was smaller.

\section{Conclusion}

Interactions between the impact of human capital investments at different developmental stages are of substantial policy interest. For instance, if such interactions are characterized by dynamic complementarity, then efficiency-equity tradeoffs are greatly mitigated for early childhood interventions - these might raise the achievement of under-privileged children even as they enhance the effectiveness of subsequent investments. In this case, reallocating budgets from late to early interventions may well be desirable.

This paper makes two contributions in this area. The first is to address Almond and Mazumder's (2013) observation that obtaining credible inferences on dynamic complementarities requires identifying two arguably exogenous shocks to investments affecting the same cohort. We do so by using variation in the access to abortion and to better schools in Romania. Our administrative data suggest that each of these has significant positive impacts on individuals' educational outcomes, but provide little indication of significant positive interactions between them. This leaves open the possibility that at least in this particular context later schooling interventions may deliver significant benefits even when they are targeted at more disadvantaged children.

Our second contribution is to show that such reduced form results may be necessary but not sufficient to isolate dynamic complementarities in the human capital production function. In particular, behavioral responses on the part of students, parents, and other actors may reinforce or undo dynamic complementarity. Our survey data, despite much smaller sample sizes, provide suggestive evidence of such responses in terms of parent and student effort.

\footnotetext{
$\overline{46}$ We use the IK bandwidth to generate these graphs but patterns are similar when using 1 point bandwidth.
} 
In short, we cannot rule out that ceteris paribus dynamic complementarities in the sense of Cunha and Heckman (2007) exist in our setting, but are undone by individuals' behavior.

There are a number of directions for future work. We have obviously presented evidence in a single setting; needless to say, Romania has a distinct set of characteristics and our findings may not necessarily generalize to other countries. In addition, we have focused on only one type of interaction, that between family and school environments. One possibility is that results may differ when one considers repeated shocks within a single environment. In addition, in terms of behavioral responses in the school setting, we have data on only children and parents; information on teachers would be of interest given their much larger role in schools. Further, our evidence pertains to shocks that are chronologically far apartfor instance, our sources of variation may have affected investments in early childhood and in high school, thus separated by several years. A question is whether the results might be different when potential interactions are more immediate.

Our results also have implications for future work that may try to address issues related to dynamic complementarities. The challenge of finding multiple sources of variation and sufficient data argues for the use of experimental settings where researchers can manipulate interventions and collect data relatively quickly. Our results suggest the need to measure and understand the behavioral responses that result from these interventions. At the same time, to the extent that experiments hold factors including behavioral responses constant, they may misrepresent even the direction of the net impacts that would emerge if interventions were taken to scale (Todd and Wolpin, 2003, and Pop-Eleches and Urquiola, 2013). 


\section{REFERENCES}

Abdulkadiroglu, A., J. Angrist, and P. Pathak (2014). The elite illusion: Achievement effects at boston and new york exam schools. Econometrica 82(1), 137-196.

Adhvaryu, A., T. Molina, A. Nyshadham, and J. Tamayo (2015). Helping children catch up: Early life shocks and the progresa experiment. Mimeo.

Aizer, A. and F. Cunha (2012). The production of human capital: Endowments, investments, and fertility. Mimeo, National Bureau of Economic Research Working Paper No. 18429.

Almond, D. and J. Currie (2011). Killing me softly: The fetal origins hypothesis. Journal of Economic Perspectives 25(3), 153-172.

Almond, D. and B. Mazumder (2013). Fetal origins and parental responses. Annual Review of Economics 5, 36-56.

Ananat, E., J. Gruber, P. Levine, and D. Staiger (2006). Abortion and selection. Mimeo, National Bureau of Economic Research Working Paper No. 12150.

Angrist, J. and W. Evans (1999). Schooling and labor market consequences of the 1970 state abortion reforms. Research in Labor Economics 18, 75-114.

Becker, G. (1964). Human capital: A theoretical and empirical analysis, with special reference to Education. Chicago: University of Chicago Press.

Becker, G. (1981). A treatise on the family. Cambridge: Harvard University Press.

Becker, G. and G. Lewis (1973). On the interaction between the quantity and quality of children. Journal of Political Economy 81, S279-S288.

Berelson, B. (1979). Romania's 1966 anti-abortion decree: The demographic experience of the first decade. Population Studies 33(July), 209-222.

Bertrand, M., E. Duflo, and S. Mullainathan (2004). How much should we trust differencesin-differences estimates. The Quarterly Journal of Economics 119(1), 249-275.

Black, S., P. Devereux, and K. Salvanes (2007). From the cradle to the labor market? the effect of birth weigh on adult outcomes. Quarterly Journal of Economics 122(1), 409-439.

CDC (2015). Abortion surveillance, united states, 2012: Surveillance summaries. Mimeo, Centers for Disease Control and Prevention.

Chetty, R., J. N. Friedman, N. Hilger, E. Saez, D. W. Schanzenbach, and D. Yagan (2011). How does your kindergarten classroom affect your earnings? evidence from project star. Quarterly Journal of Economics 126(4), 1593-1660.

Chevalier, A. and O. Marie (2015). Economic uncertainty, parental selection, and children's educational outcomes. Mimeo, IZA Discussion Paper No. 9004.

Cunha, F. and J. Heckman (2007). The technology of skill formation. American Economic Review 97(2), 31-47. 
Das, J., S. Dercon, J. Habyarimana, P. Krishnan, K. Muralidharan, and V. Sundararaman (2013). When can school inputs improve test scores? American Economic Journal: Applied Economics 5(2), 29-57.

David, H. P. (1999). From abortion to contraception: A resource to public policies and reproductive behavior in central and eastern Europe from 1917 to the present. London: Greenwood Press.

Del Boca, D., C. Flinn, and M. Wiswall (2013). Household choices and child development. Review of Economic Studies 81, 137-185.

Deming, D., J. Hastings, T. Kane, and D. Staiger (2014). School choice, school quality, and postsecondary attainment. American Economic Review 104(3), 991-1013.

Doyle, J. J. (2007). Child protection and child outcomes: Measuring the effects of foster care. American Economic Review 97(5), 1583-1610.

Goldin, C. and L. Katz (2002). The power of the pill: Oral contraceptives and women's career and marriage decisions. Journal of Political Economy 110(August), 730-770.

Grossman, M. and S. Jacobowitz (1981). Variations in infant mortality rates among counties of the united states: The roles of public policies and programs. Demography 18 (November), 695-713.

Grossman, M. and T. Joyce (1990). Unobservables, pregnancy resolutions, and birth weight production functions in new york city. Journal of Political Economy 98(November), 9831007.

Hahn, J., P. Todd, and W. van der Klaauw (2001). Identification and estimation of treatment effects with regression discontinuity design. Review of Economic Studies 69(1), 201-209.

Imbens, G. and K. Kalyanaraman (2009). Optimal bandwith choice for the regression discontinuity estimator. Mimeo, Harvard University.

Kaestner, R. and D. Lubotsky (1987). The impact of induced abortion on birth outcomes in the united states. Mimeo, National Bureau of Economic Research Working Paper No. 1757.

Kaestner, R. and D. Lubotsky (2014). Effects of age at school entry on child cognitive and behavioral development. Mimeo, University of Illinois at Chicago.

Kligman, G. (1998). The politics of duplicity: Controlling reproduction in Ceausescu's Romania. Los Angeles, CA: University of California Press.

Lee, D. and T. Lemieux (2010). Regression discontinuity designs in economics. Journal of Economic Literature 48, 281-355.

MacLeod, W. B. and M. Urquiola (2015). Reputation and school competition. American Economic Review 105(11), 3471-3488. 
Malamud, O. and C. Pop-Eleches (2010). General education versus vocational training: Evidence from an economy in transition. Review of Economics and Statistics 92(11).

McCrary, J. (2008). Manipulation of the running variable in the regression discontinuity design: A density test. Journal of Econometrics 142(2).

Meyer, B. (2005). Natural and quasi-experiments in economics. Journal of Business and Economic Statistics 13(2), 151-161.

Pop-Eleches, C. (2006). The impact of an abortion ban on socioeconomic outcomes of children: Evidence from romania. Journal of Political Economy 114(4), 744-773.

Pop-Eleches, C. (2010). The supply of birth control methods, education, and fertility: Evidence from romania. Journal of Human Resources 45(4), 971-997.

Pop-Eleches, C. and M. Urquiola (2013). Going to a better school: Effects and behavioral responses. American Economic Review 103(4), 1289-1324.

Rossin-Slater, M. and M. Wust (2015). Are different early investments complements or substitutes? long-run and intergenerational evidence from denmark. Mimeo, University of California Santa Barbara.

Royer, H. (2009). Separated at girth: U.s. twin estimates of the effects of birth weight. American Economic Journal: Applied Economics 1(1), 49-85.

The World Bank (1992). Romania: Human Resources and the Transition to a Market Economy. Washington, D.C.: The World Bank.

Todd, P. and K. Wolpin (2003). On the specification and estimation of the production function for cognitive achievement. The Economic Journal 113, F2-F33. 


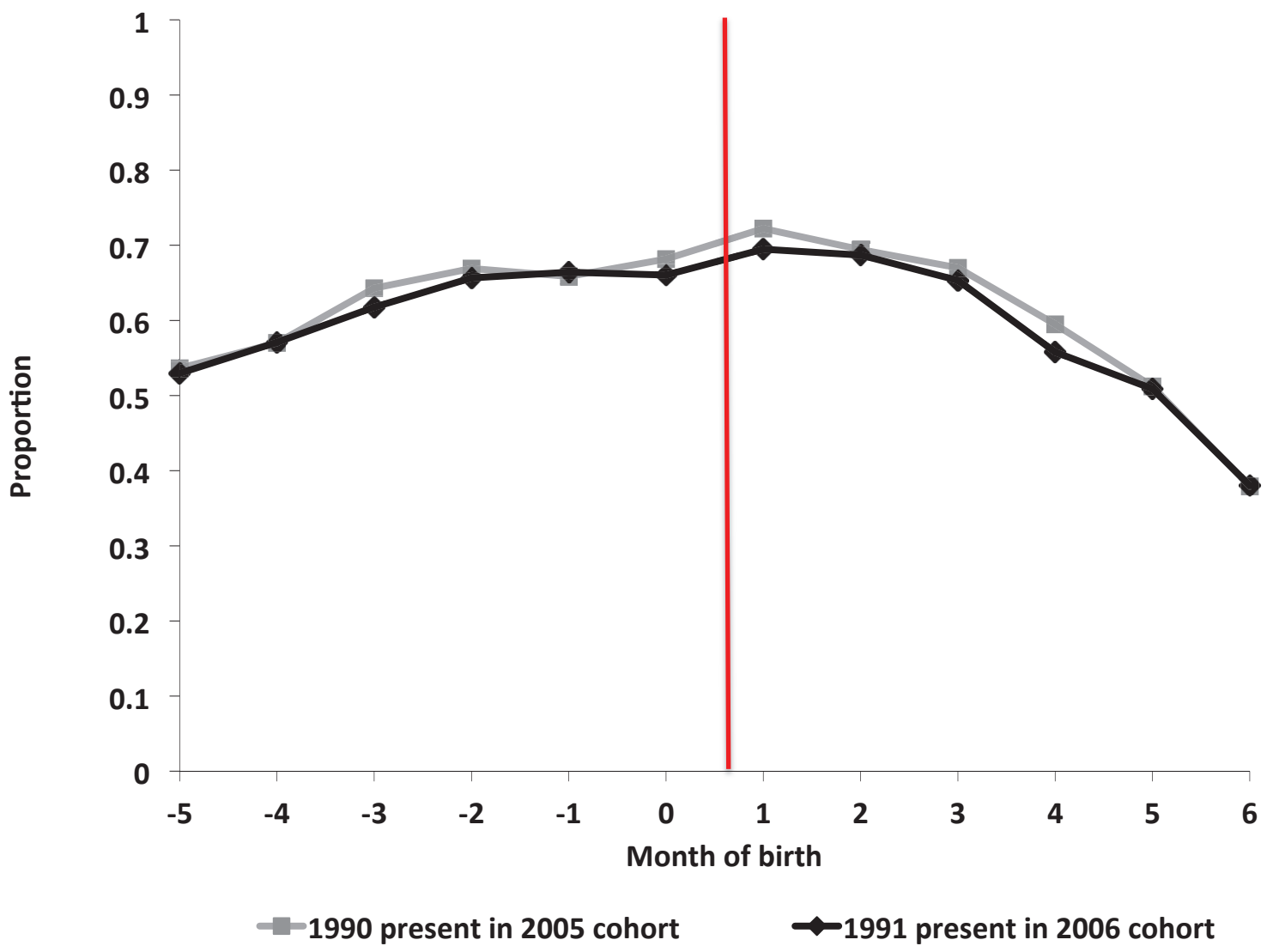

Figure 7. Proportion of births by month in admissions cohorts

Notes: This figure uses 1992 census data to plot the proportion of children born in each month. The first group is children born in 1990 present in the 2005 high school admission cohort. The second group is children born in 1991 present in the 2006 admission cohort. 


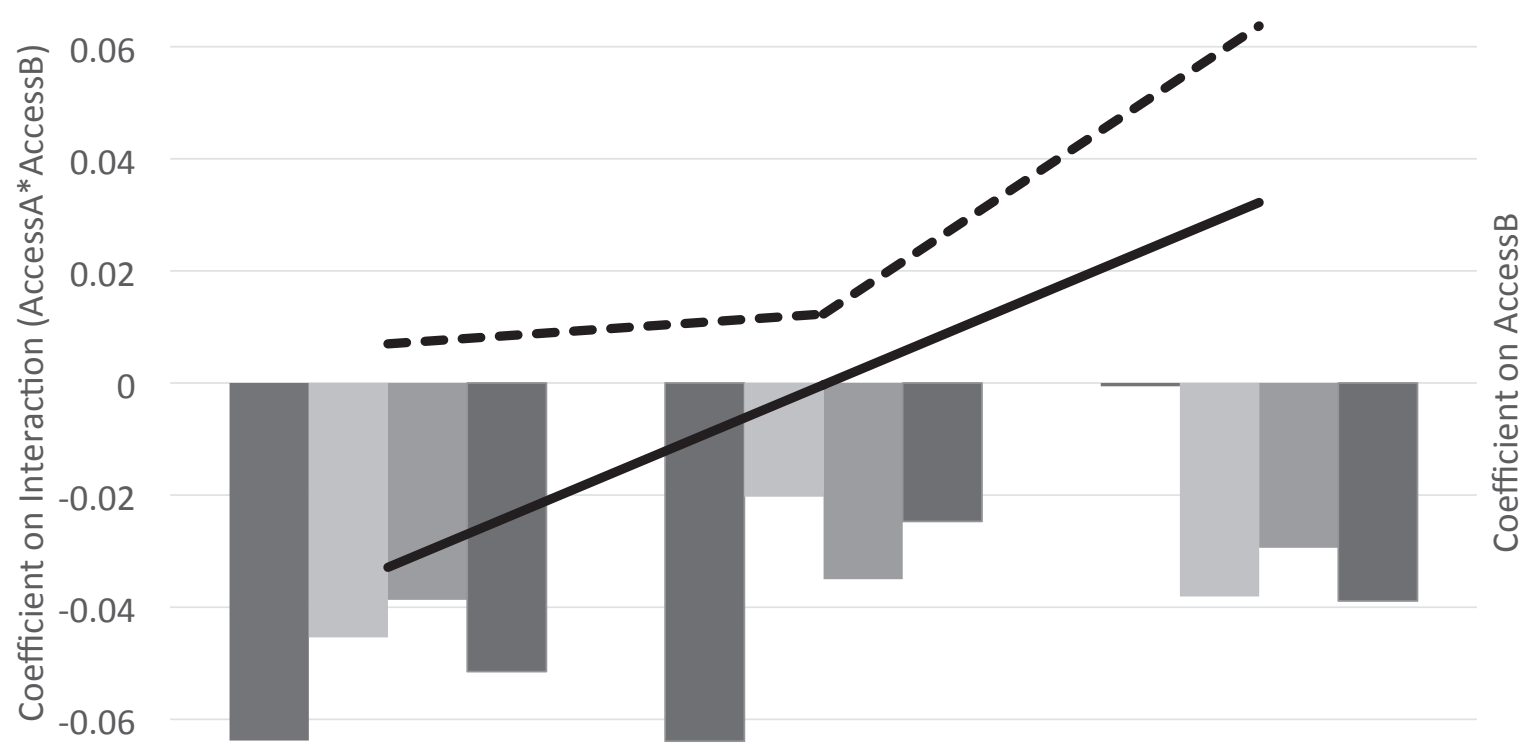

$-0.08$

Tercile 1

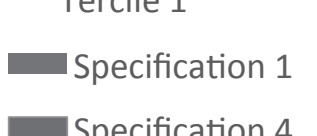

\section{Specification 1}

Specification 4 - 2005 "JAN-JUN" 2006 "JULY-DEC"
Tercile 3

Figure 8. Distribution across cutoffs

Notes: This figure plots the interaction effects between access to abortion $\left(\right.$ Access $\left.A_{i}\right)$ and access to a better school $\left(A c c e s s B_{i}\right)$ by tercile of the school quality distribution (parametrized by the transition scores of the cutoff for entry to each school) as vertical bars for each of the four specifications associated with our abortion models. It also plots the main effects of access to a better school $\left(A c c e s s B_{i}\right)$ by tercile of the school quality distribution for children who were born in 1990 before and after access to abortion as the dotted and solid lines respectively. 
TABLE 7. Descriptive statistics: All towns and survey towns

\begin{tabular}{|c|c|c|c|c|c|c|}
\hline & \multicolumn{6}{|c|}{ High school admission cohort } \\
\hline & \multicolumn{3}{|c|}{2005} & \multicolumn{3}{|c|}{2006} \\
\hline & Mean & S.D. & $\mathrm{N}$ & Mean & S.D. & $\mathrm{N}$ \\
\hline \multicolumn{7}{|l|}{ Panel A: All towns: } \\
\hline \multicolumn{7}{|l|}{ Panel A.1: Individual level } \\
\hline Transition score & 8.14 & 0.87 & 105,737 & 8.26 & 0.87 & 92,772 \\
\hline Baccalaureate taken & 0.83 & 0.38 & 105,737 & 0.85 & 0.36 & 92,772 \\
\hline Baccalaureate grade & 8.73 & 0.78 & 79,873 & 8.02 & 1.08 & 69,945 \\
\hline Romanian Bacc. grade & 7.48 & 1.59 & 87,383 & 7.80 & 1.33 & 78,243 \\
\hline \multicolumn{7}{|l|}{ Panel A.2: Track level } \\
\hline Number of $9^{\text {th }}$ grade students & 53.9 & 40.4 & 1,963 & 52.4 & 37.0 & 1,771 \\
\hline \multicolumn{7}{|l|}{ Panel A.3: School level } \\
\hline Number of $9^{\text {th }}$ grade students & 129.4 & 70.6 & 817 & 118.5 & 63.4 & 783 \\
\hline Number of tracks & 2.4 & 1.1 & 817 & 2.3 & 1.1 & 783 \\
\hline \multicolumn{7}{|l|}{ Panel A.4: Town level } \\
\hline Number of $9^{\text {th }}$ grade students & 766.2 & 839.8 & 138 & 708.2 & 757.3 & 131 \\
\hline Number of schools & 5.9 & 6.0 & 138 & 6.0 & 6.2 & 131 \\
\hline Number of tracks & 14.2 & 12.5 & 138 & 13.5 & 12.0 & 131 \\
\hline \multicolumn{7}{|l|}{ Panel B: Survey towns: } \\
\hline \multicolumn{7}{|l|}{ Panel B.1: Individual level } \\
\hline Transition score & 8.03 & 0.82 & 15,177 & 8.22 & 0.81 & 13,685 \\
\hline Baccalaureate taken & 0.83 & 0.37 & 15,177 & 0.85 & 0.36 & 13,685 \\
\hline Baccalaureate grade & 8.80 & 0.72 & 11,914 & 8.06 & 0.98 & 10,860 \\
\hline Romanian Bacc. grade & 7.61 & 1.52 & 12,623 & 7.79 & 1.25 & 11,539 \\
\hline \multicolumn{7}{|l|}{ Panel B.2: Track level } \\
\hline Number of $9^{\text {th }}$ grade students & 40.2 & 26.1 & 378 & 40.1 & 23.7 & 341 \\
\hline \multicolumn{7}{|l|}{ Panel B.3: School level } \\
\hline Number of $9^{\text {th }}$ grade students & 115.0 & 67.1 & 132 & 109.5 & 62.3 & 125 \\
\hline Number of tracks & 2.9 & 1.1 & 132 & 2.7 & 1.1 & 125 \\
\hline \multicolumn{7}{|l|}{ Panel B.4: Town level } \\
\hline Number of $9^{\text {th }}$ grade students & 257.2 & 133.6 & 59 & 244.4 & 128.7 & 56 \\
\hline Number of schools & 2.2 & 0.4 & 59 & 2.2 & 0.4 & 56 \\
\hline Number of tracks & 6.4 & 2.1 & 59 & 6.1 & 2.1 & 56 \\
\hline
\end{tabular}

Notes: This table uses the administrative data to describe two samples. Panel A describes the universe of Romanian towns with two exceptions: i) towns that make up Bucharest, and ii) towns that contain a single school. Panels A.1, A.2, A.3, and A.4 refer to characteristics at the student, track, school, and town level, respectively. Panel B presents analogous information for the towns we targeted for surveying. 
TABLE 8. Interaction effects using between track cutoffs

\begin{tabular}{|c|c|c|c|c|c|c|}
\hline & \multicolumn{2}{|c|}{ Bacc. taken } & \multicolumn{2}{|c|}{ Bacc. grade } & \multicolumn{2}{|c|}{ Romanian Bacc. grade } \\
\hline & $\begin{array}{l}\text { Within } \\
1 \text { point } \\
\text { of cutoff } \\
(1)\end{array}$ & $\begin{array}{l}\text { Within } \\
\text { IK } \\
\text { bound } \\
(2) \\
\end{array}$ & $\begin{array}{c}\text { Within } \\
1 \text { point } \\
\text { of cutoff } \\
(3)\end{array}$ & $\begin{array}{l}\text { Within } \\
\text { IK } \\
\text { bound } \\
(4) \\
\end{array}$ & $\begin{array}{c}\text { Within } \\
1 \text { point } \\
\text { of cutoff } \\
(5)\end{array}$ & $\begin{array}{l}\text { Within } \\
\text { IK } \\
\text { bound } \\
(6) \\
\end{array}$ \\
\hline \multicolumn{7}{|l|}{ Panel A: 2005 cohorts } \\
\hline Access to a better school (AccessB) & $\begin{array}{c}-0.006 \\
{[0.014]}\end{array}$ & $\begin{array}{c}-0.008 \\
{[0.014]}\end{array}$ & $\begin{array}{c}0.013 \\
{[0.011]}\end{array}$ & $\begin{array}{c}0.008 \\
{[0.017]}\end{array}$ & $\begin{array}{c}0.012 \\
{[0.011]}\end{array}$ & $\begin{array}{c}-0.005 \\
{[0.017]}\end{array}$ \\
\hline Abortion access $($ Access $A)$ & $\begin{array}{c}0.029 \\
{[0.018]}\end{array}$ & $\begin{array}{c}0.029 \\
{[0.018]}\end{array}$ & $\begin{array}{c}0.007 \\
{[0.016]}\end{array}$ & $\begin{array}{c}0.021 \\
{[0.019]}\end{array}$ & $\begin{array}{c}0.003 \\
{[0.017]}\end{array}$ & $\begin{array}{c}0.009 \\
{[0.019]}\end{array}$ \\
\hline AccessB ${ }^{*}$ Access $A$ & $\begin{array}{c}0.025 * \\
{[0.014]}\end{array}$ & $\begin{array}{c}0.026 * * \\
{[0.013]}\end{array}$ & $\begin{array}{c}-0.011 \\
{[0.012]}\end{array}$ & $\begin{array}{c}-0.045 * * \\
{[0.018]}\end{array}$ & $\begin{array}{c}-0.013 \\
{[0.012]}\end{array}$ & $\begin{array}{l}-0.027 \\
{[0.018]}\end{array}$ \\
\hline Monthly trend & $\mathrm{Y}$ & $\mathrm{Y}$ & $\mathrm{Y}$ & $\mathrm{Y}$ & $\mathrm{Y}$ & $\mathrm{Y}$ \\
\hline Calendar month dummies & $\mathrm{N}$ & $\mathrm{N}$ & $\mathrm{N}$ & $\mathrm{N}$ & $\mathrm{N}$ & $\mathrm{N}$ \\
\hline Cohort dummy & $\mathrm{N}$ & $\mathrm{N}$ & $\mathrm{N}$ & $\mathrm{N}$ & $\mathrm{N}$ & $\mathrm{N}$ \\
\hline $\mathrm{N}$ & $1,282,007$ & $1,357,609$ & 955,918 & 370,150 & $1,057,456$ & 430,879 \\
\hline \multicolumn{7}{|l|}{ Panel B: 2005 and 2006 cohorts } \\
\hline Access to a better school (AccessB) & $\begin{array}{c}-0.001 \\
{[0.008]}\end{array}$ & $\begin{array}{l}-0.004 \\
{[0.009]}\end{array}$ & $\begin{array}{c}0.012 * \\
{[0.007]}\end{array}$ & $\begin{array}{c}0.018 \\
{[0.012]}\end{array}$ & $\begin{array}{c}0.007 \\
{[0.007]}\end{array}$ & $\begin{array}{c}0.013 \\
{[0.012]}\end{array}$ \\
\hline Abortion access (Access $A)$ & $\begin{array}{l}0.027 * * \\
{[0.014]}\end{array}$ & $\begin{array}{c}0.025^{*} \\
{[0.014]}\end{array}$ & $\begin{array}{c}0.002 \\
{[0.013]}\end{array}$ & $\begin{array}{c}0.009 \\
{[0.015]}\end{array}$ & $\begin{array}{c}-0.010 \\
{[0.012]}\end{array}$ & $\begin{array}{l}-0.009 \\
{[0.014]}\end{array}$ \\
\hline$A c c e s s B^{*} A c c e s s A$ & $\begin{array}{l}-0.013 \\
{[0.010]}\end{array}$ & $\begin{array}{l}-0.010 \\
{[0.010]}\end{array}$ & $\begin{array}{c}-0.002 \\
{[0.009]}\end{array}$ & $\begin{array}{c}-0.008 \\
{[0.014]}\end{array}$ & $\begin{array}{l}-0.001 \\
{[0.009]}\end{array}$ & $\begin{array}{c}-0.008 \\
{[0.014]}\end{array}$ \\
\hline Monthly trend & $\mathrm{N}$ & $\mathrm{N}$ & $\mathrm{N}$ & $\mathrm{N}$ & $\mathrm{N}$ & $\mathrm{N}$ \\
\hline Calendar month dummies & $\mathrm{N}$ & $\mathrm{N}$ & $\mathrm{N}$ & $\mathrm{N}$ & $\mathrm{N}$ & $\mathrm{N}$ \\
\hline Cohort dummy & $\mathrm{Y}$ & $\mathrm{Y}$ & $\mathrm{Y}$ & $\mathrm{Y}$ & $\mathrm{Y}$ & $\mathrm{Y}$ \\
\hline $\mathrm{N}$ & $2,369,850$ & $2,508,244$ & $1,771,248$ & 689,545 & $1,978,326$ & 810,102 \\
\hline \multicolumn{7}{|l|}{ Panel C: 2005 and 2006 cohorts } \\
\hline Access to a better school (Access B) & $\begin{array}{c}-0.022 * * \\
{[0.010]}\end{array}$ & $\begin{array}{c}-0.023 * * \\
{[0.010]}\end{array}$ & $\begin{array}{c}0.015 * \\
{[0.008]}\end{array}$ & $\begin{array}{c}0.033 * * * \\
{[0.013]}\end{array}$ & $\begin{array}{c}0.015 * \\
{[0.008]}\end{array}$ & $\begin{array}{c}0.001 \\
{[0.013]}\end{array}$ \\
\hline Abortion access (Access $A)$ & $\begin{array}{c}0.030 * * \\
{[0.012]}\end{array}$ & $\begin{array}{l}0.030 * * \\
{[0.012]}\end{array}$ & $\begin{array}{c}0.011 \\
{[0.011]}\end{array}$ & $\begin{array}{c}0.020 \\
{[0.013]}\end{array}$ & $\begin{array}{l}-0.002 \\
{[0.011]}\end{array}$ & $\begin{array}{c}0.003 \\
{[0.013]}\end{array}$ \\
\hline $\operatorname{Access} B^{*}$ Access $A$ & $\begin{array}{c}-0.002 \\
{[0.00918]}\end{array}$ & $\begin{array}{c}-0.001 \\
{[0.00888]}\end{array}$ & $\begin{array}{c}-0.007 \\
{[0.00773]}\end{array}$ & $\begin{array}{c}-0.0242 * * \\
{[0.0120]}\end{array}$ & $\begin{array}{c}-0.008 \\
{[0.00792]}\end{array}$ & $\begin{array}{c}-0.0207 * \\
{[0.0122]}\end{array}$ \\
\hline Monthly trend & $\mathrm{Y}$ & $\mathrm{Y}$ & $\mathrm{Y}$ & $\mathrm{Y}$ & $\mathrm{Y}$ & $\mathrm{Y}$ \\
\hline Calendar month dummies & $\mathrm{N}$ & $\mathrm{N}$ & $\mathrm{N}$ & $\mathrm{N}$ & $\mathrm{N}$ & $\mathrm{N}$ \\
\hline Cohort dummy & $\mathrm{Y}$ & $\mathrm{Y}$ & $\mathrm{Y}$ & $\mathrm{Y}$ & $\mathrm{Y}$ & $\mathrm{Y}$ \\
\hline $\mathrm{N}$ & $2,369,850$ & $2,508,244$ & $1,771,248$ & 689,545 & $1,978,326$ & 810,102 \\
\hline \multicolumn{7}{|l|}{ Panel D: 2005 and 2006 cohorts } \\
\hline Access to a better school (Access $B)$ & $\begin{array}{c}-0.026^{*} \\
{[0.015]}\end{array}$ & $\begin{array}{c}-0.027 * \\
{[0.015]}\end{array}$ & $\begin{array}{c}0.033 * * \\
{[0.013]}\end{array}$ & $\begin{array}{c}0.038 * \\
{[0.020]}\end{array}$ & $\begin{array}{c}0.010 \\
{[0.013]}\end{array}$ & $\begin{array}{c}0.005 \\
{[0.020]}\end{array}$ \\
\hline Abortion access (Access $A$ ) & $\begin{array}{c}0.027 * \\
{[0.014]}\end{array}$ & $\begin{array}{c}0.025 * \\
{[0.014]}\end{array}$ & $\begin{array}{c}0.002 \\
{[0.013]}\end{array}$ & $\begin{array}{c}0.009 \\
{[0.015]}\end{array}$ & $\begin{array}{c}-0.011 \\
{[0.012]}\end{array}$ & $\begin{array}{l}-0.008 \\
{[0.014]}\end{array}$ \\
\hline $\operatorname{Access} B^{*}$ Access $A$ & $\begin{array}{c}-0.013 \\
{[0.010]}\end{array}$ & $\begin{array}{l}-0.010 \\
{[0.010]}\end{array}$ & $\begin{array}{c}-0.002 \\
{[0.009]}\end{array}$ & $\begin{array}{c}-0.009 \\
{[0.014]}\end{array}$ & $\begin{array}{l}-0.001 \\
{[0.009]}\end{array}$ & $\begin{array}{l}-0.009 \\
{[0.014]}\end{array}$ \\
\hline Monthly trend & $\mathrm{N}$ & $\mathrm{N}$ & $\mathrm{N}$ & $\mathrm{N}$ & $\mathrm{N}$ & $\mathrm{N}$ \\
\hline Calendar month dummies & $\mathrm{Y}$ & $\mathrm{Y}$ & $\mathrm{Y}$ & $\mathrm{Y}$ & $\mathrm{Y}$ & $\mathrm{Y}$ \\
\hline Cohort dummy & $\mathrm{Y}$ & $\mathrm{Y}$ & $\mathrm{Y}$ & $\mathrm{Y}$ & $\mathrm{Y}$ & $\mathrm{Y}$ \\
\hline $\mathrm{N}$ & $2,369,850$ & $2,508,244$ & $1,771,248$ & 689,545 & $1,978,326$ & 810,102 \\
\hline
\end{tabular}

Notes: These regressions implement specification (15). They are clustered at the student level and include cutoff fixed effects, where the cutoffs are those between tracks. Standard errors are in brackets. All panels present reduced form specifications where the key independent variable is a dummy for the interaction of access to abortion and access to a better school. ${ }^{*} p<0.10,{ }^{* *} p<0.05,{ }^{* * *} p<0.01$. 
TABLE 9. Interaction effects among survey respondents

\begin{tabular}{|c|c|c|c|c|c|c|}
\hline & \multicolumn{2}{|c|}{ Bacc. taken } & \multicolumn{2}{|c|}{ Bacc. grade } & \multicolumn{2}{|c|}{ Romanian Bacc. grade } \\
\hline & $\begin{array}{c}\text { Within } \\
1 \text { point } \\
\text { of cutoff } \\
\text { (1) }\end{array}$ & $\begin{array}{l}\text { Within } \\
\text { IK } \\
\text { bound } \\
(2) \\
\end{array}$ & $\begin{array}{c}\text { Within } \\
1 \text { point } \\
\text { of cutoff } \\
\text { (3) }\end{array}$ & $\begin{array}{l}\text { Within } \\
\text { IK } \\
\text { bound } \\
(4) \\
\end{array}$ & $\begin{array}{c}\text { Within } \\
1 \text { point } \\
\text { of cutoff } \\
(5)\end{array}$ & $\begin{array}{l}\text { Within } \\
\text { IK } \\
\text { bound } \\
(6) \\
\end{array}$ \\
\hline \multicolumn{7}{|l|}{ Panel A: 2005 cohort } \\
\hline Access to a better school (Access $B)$ & $\begin{array}{c}0.071 \\
{[0.093]}\end{array}$ & $\begin{array}{c}0.066 \\
{[0.089]}\end{array}$ & $\begin{array}{c}0.182 \\
{[0.287]}\end{array}$ & $\begin{array}{c}0.131 \\
{[0.263]}\end{array}$ & $\begin{array}{c}0.141 \\
{[0.312]}\end{array}$ & $\begin{array}{c}0.162 \\
{[0.251]}\end{array}$ \\
\hline Abortion access (Access $A)$ & $\begin{array}{l}-0.095 \\
{[0.070]}\end{array}$ & $\begin{array}{c}-0.028 \\
{[0.062]}\end{array}$ & $\begin{array}{c}0.127 \\
{[0.235]}\end{array}$ & $\begin{array}{c}0.072 \\
{[0.223]}\end{array}$ & $\begin{array}{c}0.510 * * \\
{[0.219]}\end{array}$ & $\begin{array}{c}0.294 \\
{[0.200]}\end{array}$ \\
\hline Access $B^{*}$ Access $A$ & $\begin{array}{c}0.115 \\
{[0.091]}\end{array}$ & $\begin{array}{c}0.041 \\
{[0.078]}\end{array}$ & $\begin{array}{c}-0.111 \\
{[0.295]}\end{array}$ & $\begin{array}{c}-0.072 \\
{[0.274]}\end{array}$ & $\begin{array}{c}-0.396 \\
{[0.293]}\end{array}$ & $\begin{array}{c}-0.210 \\
{[0.238]}\end{array}$ \\
\hline Monthly trend & $\mathrm{Y}$ & $\mathrm{Y}$ & $\mathrm{Y}$ & $\mathrm{Y}$ & $\mathrm{Y}$ & $\mathrm{Y}$ \\
\hline Calendar month dummies & $\mathrm{N}$ & $\mathrm{N}$ & $\mathrm{N}$ & $\mathrm{N}$ & $\mathrm{N}$ & $\mathrm{N}$ \\
\hline Cohort dummy & $\mathrm{N}$ & $\mathrm{N}$ & $\mathrm{N}$ & $\mathrm{N}$ & $\mathrm{N}$ & $\mathrm{N}$ \\
\hline $\mathrm{N}$ & 1,851 & 2,267 & 1,571 & 1,908 & 1,721 & 2,880 \\
\hline \multicolumn{7}{|l|}{ Panel B: 2005 and 2006 cohorts } \\
\hline Access to a better school (Access $B)$ & $\begin{array}{c}0.054 \\
{[0.062]}\end{array}$ & $\begin{array}{c}0.082 \\
{[0.057]}\end{array}$ & $\begin{array}{c}0.224 \\
{[0.189]}\end{array}$ & $\begin{array}{c}0.177 \\
{[0.159]}\end{array}$ & $\begin{array}{c}0.477 * * \\
{[0.195]}\end{array}$ & $\begin{array}{c}0.391 * * \\
{[0.157]}\end{array}$ \\
\hline Abortion access (Access $A)$ & $\begin{array}{c}-0.021 \\
{[0.058]}\end{array}$ & $\begin{array}{c}-0.002 \\
{[0.053]}\end{array}$ & $\begin{array}{c}0.220 \\
{[0.177]}\end{array}$ & $\begin{array}{c}0.178 \\
{[0.164]}\end{array}$ & $\begin{array}{c}0.240 \\
{[0.182]}\end{array}$ & $\begin{array}{c}0.181 \\
{[0.160]}\end{array}$ \\
\hline $\operatorname{Access} B^{*} A \operatorname{ccess} A$ & $\begin{array}{c}-0.058 \\
{[0.072]}\end{array}$ & $\begin{array}{c}-0.065 \\
{[0.066]}\end{array}$ & $\begin{array}{c}-0.241 \\
{[0.222]}\end{array}$ & $\begin{array}{l}-0.169 \\
{[0.186]}\end{array}$ & $\begin{array}{c}-0.366 \\
{[0.233]}\end{array}$ & $\begin{array}{c}-0.316^{*} \\
{[0.187]}\end{array}$ \\
\hline Monthly trend & $\mathrm{N}$ & $\mathrm{N}$ & $\mathrm{N}$ & $\mathrm{N}$ & $\mathrm{N}$ & $\mathrm{N}$ \\
\hline Calendar month dummies & $\mathrm{N}$ & $\mathrm{N}$ & $\mathrm{N}$ & $\mathrm{N}$ & $\mathrm{N}$ & $\mathrm{N}$ \\
\hline Cohort dummy & Y & $\mathrm{Y}$ & $\mathrm{Y}$ & $\mathrm{Y}$ & $\mathrm{Y}$ & $\mathrm{Y}$ \\
\hline $\mathrm{N}$ & 3,558 & 4,244 & 3,012 & 5,309 & 3,303 & 5,445 \\
\hline \multicolumn{7}{|l|}{ Panel C: 2005 and 2006 cohorts } \\
\hline Access to a better school (AccessB) & $\begin{array}{c}0.019 \\
{[0.066]}\end{array}$ & $\begin{array}{c}0.019 \\
{[0.063]}\end{array}$ & $\begin{array}{c}0.012 \\
{[0.204]}\end{array}$ & $\begin{array}{c}0.039 \\
{[0.171]}\end{array}$ & $\begin{array}{c}-0.046 \\
{[0.219]}\end{array}$ & $\begin{array}{c}-0.062 \\
{[0.177]}\end{array}$ \\
\hline Abortion access $($ Access $A)$ & $\begin{array}{c}-0.060 \\
{[0.050]}\end{array}$ & $\begin{array}{l}-0.030 \\
{[0.046]}\end{array}$ & $\begin{array}{c}0.212 \\
{[0.154]}\end{array}$ & $\begin{array}{c}0.147 \\
{[0.141]}\end{array}$ & $\begin{array}{c}0.287 * \\
{[0.156]}\end{array}$ & $\begin{array}{c}0.179 \\
{[0.139]}\end{array}$ \\
\hline Access $B^{*}$ Access $A$ & $\begin{array}{c}0.021 \\
{[0.062]}\end{array}$ & $\begin{array}{c}-0.007 \\
{[0.056]}\end{array}$ & $\begin{array}{c}-0.155 \\
{[0.193]}\end{array}$ & $\begin{array}{c}-0.112 \\
{[0.161]}\end{array}$ & $\begin{array}{c}-0.336^{*} \\
{[0.203]}\end{array}$ & $\begin{array}{c}-0.237 \\
{[0.164]}\end{array}$ \\
\hline Monthly trend & $\mathrm{Y}$ & $\mathrm{Y}$ & $\mathrm{Y}$ & $\mathrm{Y}$ & $\mathrm{Y}$ & $\mathrm{Y}$ \\
\hline Calendar month dummies & $\mathrm{N}$ & $\mathrm{N}$ & $\mathrm{N}$ & $\mathrm{N}$ & $\mathrm{N}$ & $\mathrm{N}$ \\
\hline Cohort dummy & $\mathrm{Y}$ & $\mathrm{Y}$ & Y & $\mathrm{Y}$ & Y & $\mathrm{Y}$ \\
\hline $\mathrm{N}$ & 3,558 & 4,244 & 3,012 & 5,309 & 3,303 & 5,445 \\
\hline \multicolumn{7}{|l|}{ Panel D: 2005 and 2006 cohorts } \\
\hline Access to a better school (AccessB) & $\begin{array}{c}-0.048 \\
{[0.084]}\end{array}$ & $\begin{array}{c}-0.019 \\
{[0.084]}\end{array}$ & $\begin{array}{c}0.177 \\
{[0.291]}\end{array}$ & $\begin{array}{c}0.261 \\
{[0.240]}\end{array}$ & $\begin{array}{c}0.442 \\
{[0.338]}\end{array}$ & $\begin{array}{c}0.326 \\
{[0.260]}\end{array}$ \\
\hline Abortion access $($ Access $A)$ & $\begin{array}{c}-0.029 \\
{[0.059]}\end{array}$ & $\begin{array}{l}-0.008 \\
{[0.055]}\end{array}$ & $\begin{array}{c}0.224 \\
{[0.180]}\end{array}$ & $\begin{array}{c}0.166 \\
{[0.167]}\end{array}$ & $\begin{array}{c}0.250 \\
{[0.186]}\end{array}$ & $\begin{array}{c}0.186 \\
{[0.164]}\end{array}$ \\
\hline$A c c e s s B^{*} A c c e s s A$ & $\begin{array}{c}-0.051 \\
{[0.073]}\end{array}$ & $\begin{array}{c}-0.061 \\
{[0.067]}\end{array}$ & $\begin{array}{c}-0.246 \\
{[0.226]}\end{array}$ & $\begin{array}{c}-0.168 \\
{[0.189]}\end{array}$ & $\begin{array}{c}-0.366 \\
{[0.238]}\end{array}$ & $\begin{array}{l}-0.328 * \\
{[0.192]}\end{array}$ \\
\hline Monthly trend & $\mathrm{N}$ & $\mathrm{N}$ & $\mathrm{N}$ & $\mathrm{N}$ & $\mathrm{N}$ & $\mathrm{N}$ \\
\hline Calendar month dummies & $\mathrm{Y}$ & $\mathrm{Y}$ & $\mathrm{Y}$ & $\mathrm{Y}$ & $\mathrm{Y}$ & $\mathrm{Y}$ \\
\hline Cohort dummy & Y & Y & Y & Y & $\mathrm{Y}$ & $\mathrm{Y}$ \\
\hline $\mathrm{N}$ & 3,558 & 4,244 & 3,012 & 5,309 & 3,303 & 5,445 \\
\hline
\end{tabular}

Notes: These regressions implement specification (15) for the sample of survey respondesnts. They are clustered at the student level and include cutoff fixed effects, where the cutoffs are those between tracks. Standard errors are in brackets. All panels present reduced form specifications where the key independent variable is a dummy for the interaction of access to abortion and access to a better school. ${ }^{*} p<0.10,{ }^{* *}$ $p<0.05, * * * p<0.01$. 
TABLE 10. The effect of access to abortion on mothers' characteristics

\begin{tabular}{|c|c|c|c|c|}
\hline \multicolumn{5}{|c|}{ "Panel A: Markers of mothers' socioeconomic status } \\
\hline \multirow[t]{2}{*}{ Dependent variable: } & Primary education & $\begin{array}{l}\text { Secondary } \\
\text { education }\end{array}$ & Higher education & $\begin{array}{c}\text { Urban region of } \\
\text { birth }\end{array}$ \\
\hline & (1) & (2) & (3) & (4) \\
\hline \multirow[t]{2}{*}{ Access to abortion (Access $A)$} & -0.006 & 0.002 & 0.004 & -0.007 \\
\hline & [0.004] & [0.004] & {$[0.002]$} & {$[0.005]$} \\
\hline Monthly trend & $\mathrm{Y}$ & Y & $\mathrm{Y}$ & Y \\
\hline Calendar month dummies & $\mathrm{N}$ & $\mathrm{N}$ & $\mathrm{N}$ & $\mathrm{N}$ \\
\hline Cohort dummy & Y & Y & Y & Y \\
\hline Cohorts included & $2005 / 2006$ & $2005 / 2006$ & $2005 / 2006$ & $2005 / 2006$ \\
\hline $\mathrm{N}$ & 86,408 & 86,408 & 86,408 & 86,755 \\
\hline \multicolumn{5}{|c|}{$\begin{array}{l}\text { Panel B: Markers of unwantedness } \\
\end{array}$} \\
\hline Dependent variable: & $\begin{array}{l}\text { Married } \\
\text { (1) }\end{array}$ & $\begin{array}{c}\text { Divorced } \\
(2)\end{array}$ & $\begin{array}{l}\text { No. of children } \\
\text { (3) }\end{array}$ & $\begin{array}{l}\text { Age } \\
(4)\end{array}$ \\
\hline$\overline{\text { Access to abortion }(\text { Access } A)}$ & $\begin{array}{c}0.007 * * * \\
{[0.003]}\end{array}$ & $\begin{array}{l}-0.001 \\
{[0.001]}\end{array}$ & $\begin{array}{c}-0.146^{* * * *} \\
{[0.022]}\end{array}$ & $\begin{array}{c}-0.257 * * \\
{[0.116]}\end{array}$ \\
\hline Monthly trend & $\mathrm{Y}$ & $\mathrm{Y}$ & Y & $\mathrm{Y}$ \\
\hline Calendar month dummies & $\mathrm{N}$ & $\mathrm{N}$ & $\mathrm{N}$ & $\mathrm{N}$ \\
\hline Cohort dummy & $\mathrm{Y}$ & Y & $\mathrm{Y}$ & $\mathrm{Y}$ \\
\hline Cohorts included & $2005 / 2006$ & $2005 / 2006$ & $2005 / 2006$ & $2005 / 2006$ \\
\hline $\mathrm{N}$ & 86,758 & 86,774 & 86,373 & 86,389 \\
\hline
\end{tabular}

Notes: These regressions estimate specification (12) with maternal characteristics as outcome variables. Standard errors are in brackets and are clustered by age in months. The abortion access dummy (AccessA) equals 1 for mothers who gave birth on or after July 1, 1990, and equals 0 for mothers who gave birth on or before June 30, 1990. ${ }^{*} p<0.10,{ }^{* *} p<0.05,{ }^{* * *} p<0.01$. 
TABLE 11. Interactions controlling for non-poor status

\begin{tabular}{|c|c|c|c|c|c|c|}
\hline & \multicolumn{2}{|c|}{ Bacc. taken } & \multicolumn{2}{|c|}{ Bacc. grade } & \multicolumn{2}{|c|}{ Romanian Bacc. grade } \\
\hline & $\begin{array}{l}\text { Within } \\
1 \text { point } \\
\text { of cutoff } \\
\text { (1) }\end{array}$ & $\begin{array}{l}\text { Within } \\
\text { IK } \\
\text { bound } \\
(2)\end{array}$ & $\begin{array}{c}\text { Within } \\
1 \text { point } \\
\text { of cutoff } \\
\text { (3) }\end{array}$ & $\begin{array}{l}\text { Within } \\
\text { IK } \\
\text { bound } \\
(4)\end{array}$ & $\begin{array}{c}\text { Within } \\
1 \text { point } \\
\text { of cutoff } \\
(5)\end{array}$ & $\begin{array}{l}\text { Within } \\
\text { IK } \\
\text { bound } \\
(6)\end{array}$ \\
\hline \multicolumn{7}{|l|}{ Panel A } \\
\hline Access to a better school (Access $B)$ & $\begin{array}{c}0.006 \\
{[0.016]}\end{array}$ & $\begin{array}{c}0.012 \\
{[0.017]}\end{array}$ & $\begin{array}{c}0.026 * * \\
{[0.013]}\end{array}$ & $\begin{array}{c}0.012 \\
{[0.019]}\end{array}$ & $\begin{array}{c}0.013 \\
{[0.013]}\end{array}$ & $\begin{array}{c}0.002 \\
{[0.017]}\end{array}$ \\
\hline Abortion access $($ Access $A)$ & $\begin{array}{c}0.024 \\
{[0.017]}\end{array}$ & $\begin{array}{c}0.022 \\
{[0.017]}\end{array}$ & $\begin{array}{c}0.017 \\
{[0.014]}\end{array}$ & $\begin{array}{c}0.019 \\
{[0.017]}\end{array}$ & $\begin{array}{c}0.006 \\
{[0.014]}\end{array}$ & $\begin{array}{c}0.021 \\
{[0.016]}\end{array}$ \\
\hline $\operatorname{Access} B^{*}$ Access $A$ & $\begin{array}{c}0.002 \\
{[0.015]}\end{array}$ & $\begin{array}{c}0.005 \\
{[0.016]}\end{array}$ & $\begin{array}{c}-0.010 \\
{[0.013]}\end{array}$ & $\begin{array}{c}-0.037 * * \\
{[0.018]}\end{array}$ & $\begin{array}{c}-0.017 \\
{[0.013]}\end{array}$ & $\begin{array}{c}-0.037 * * \\
{[0.017]}\end{array}$ \\
\hline Monthly trend & $\mathrm{Y}$ & $\mathrm{Y}$ & $\mathrm{Y}$ & $\mathrm{Y}$ & $\mathrm{Y}$ & $\mathrm{Y}$ \\
\hline Calendar month dummies & $\mathrm{N}$ & $\mathrm{N}$ & $\mathrm{N}$ & $\mathrm{N}$ & $\mathrm{N}$ & $\mathrm{N}$ \\
\hline Cohort dummy & $\mathrm{Y}$ & $\mathrm{Y}$ & $\mathrm{Y}$ & $\mathrm{Y}$ & $\mathrm{Y}$ & $\mathrm{Y}$ \\
\hline $\mathrm{N}$ & 892,225 & 778,491 & 626,761 & 315,590 & 723,055 & 453,822 \\
\hline Panel B & & & & & & \\
\hline Access to a better school (AccessB) & $\begin{array}{c}0.010 \\
{[0.021]}\end{array}$ & $\begin{array}{c}0.015 \\
{[0.023]}\end{array}$ & $\begin{array}{c}0.0316^{*} \\
{[0.018]}\end{array}$ & $\begin{array}{c}0.018 \\
{[0.025]}\end{array}$ & $\begin{array}{c}0.017 \\
{[0.018]}\end{array}$ & $\begin{array}{c}-0.012 \\
{[0.022]}\end{array}$ \\
\hline Nonpoor dummy & $\begin{array}{c}0.129 * * * \\
{[0.016]}\end{array}$ & $\begin{array}{c}0.128 * * * \\
{[0.017]}\end{array}$ & $\begin{array}{c}0.148^{* * *} \\
{[0.014]}\end{array}$ & $\begin{array}{c}0.139 * * * \\
{[0.017]}\end{array}$ & $\begin{array}{c}0.090 * * * \\
{[0.013]}\end{array}$ & $\begin{array}{c}0.081 * * * \\
{[0.015]}\end{array}$ \\
\hline Access $B^{*}$ Nonpoor & $\begin{array}{c}-0.006 \\
{[0.016]}\end{array}$ & $\begin{array}{c}-0.004 \\
{[0.017]}\end{array}$ & $\begin{array}{c}-0.007 \\
{[0.013]}\end{array}$ & $\begin{array}{c}-0.010 \\
{[0.018]}\end{array}$ & $\begin{array}{c}-0.007 \\
{[0.013]}\end{array}$ & $\begin{array}{c}0.013 \\
{[0.016]}\end{array}$ \\
\hline Monthly trend & $\mathrm{Y}$ & $\mathrm{Y}$ & $\mathrm{Y}$ & $\mathrm{Y}$ & $\mathrm{Y}$ & $\mathrm{Y}$ \\
\hline Calendar month dummies & $\mathrm{N}$ & $\mathrm{N}$ & $\mathrm{N}$ & $\mathrm{N}$ & $\mathrm{N}$ & $\mathrm{N}$ \\
\hline Cohort dummy & $\mathrm{Y}$ & $\mathrm{Y}$ & $\mathrm{Y}$ & $\mathrm{Y}$ & $\mathrm{Y}$ & $\mathrm{Y}$ \\
\hline $\mathrm{N}$ & 892,225 & 778,491 & 626,761 & 315,590 & 723,055 & 453,822 \\
\hline Panel C & & & & & & \\
\hline Access to a better school (Access $B)$ & $\begin{array}{c}0.010 \\
{[0.021]}\end{array}$ & $\begin{array}{c}0.015 \\
{[0.023]}\end{array}$ & $\begin{array}{c}0.032 * \\
{[0.018]}\end{array}$ & $\begin{array}{c}0.019 \\
{[0.025]}\end{array}$ & $\begin{array}{c}0.018 \\
{[0.018]}\end{array}$ & $\begin{array}{c}-0.010 \\
{[0.022]}\end{array}$ \\
\hline Abortion access $($ Access $A)$ & $\begin{array}{c}0.024 \\
{[0.016]}\end{array}$ & $\begin{array}{c}0.022 \\
{[0.017]}\end{array}$ & $\begin{array}{c}0.017 \\
{[0.014]}\end{array}$ & $\begin{array}{c}0.019 \\
{[0.017]}\end{array}$ & $\begin{array}{c}0.006 \\
{[0.014]}\end{array}$ & $\begin{array}{c}0.021 \\
{[0.016]}\end{array}$ \\
\hline Access $B^{*}$ Access $A$ & $\begin{array}{c}0.002 \\
{[0.015]}\end{array}$ & $\begin{array}{c}0.005 \\
{[0.016]}\end{array}$ & $\begin{array}{l}-0.010 \\
{[0.013]}\end{array}$ & $\begin{array}{c}-0.036^{* *} \\
{[0.018]}\end{array}$ & $\begin{array}{c}-0.017 \\
{[0.013]}\end{array}$ & $\begin{array}{c}-0.037 * * \\
{[0.017]}\end{array}$ \\
\hline Nonpoor dummy & $\begin{array}{c}0.129 * * * \\
{[0.016]}\end{array}$ & $\begin{array}{c}0.128 * * * \\
{[0.017]}\end{array}$ & $\begin{array}{c}0.148 * * * \\
{[0.014]}\end{array}$ & $\begin{array}{c}0.139 * * * \\
{[0.017]}\end{array}$ & $\begin{array}{c}0.090 * * * \\
{[0.013]}\end{array}$ & $\begin{array}{c}0.081 * * * \\
{[0.015]}\end{array}$ \\
\hline Access $B *$ Nonpoor & $\begin{array}{c}-0.006 \\
{[0.0155]}\end{array}$ & $\begin{array}{c}-0.004 \\
{[0.0167]}\end{array}$ & $\begin{array}{c}-0.007 \\
{[0.0127]}\end{array}$ & $\begin{array}{c}-0.009 \\
{[0.0183]}\end{array}$ & $\begin{array}{c}-0.007 \\
{[0.0126]}\end{array}$ & $\begin{array}{c}0.013 \\
{[0.0161]}\end{array}$ \\
\hline Monthly trend & $\mathrm{Y}$ & $\mathrm{Y}$ & $\mathrm{Y}$ & $\mathrm{Y}$ & $\mathrm{Y}$ & $\mathrm{Y}$ \\
\hline Calendar month dummies & $\mathrm{N}$ & $\mathrm{N}$ & $\mathrm{N}$ & $\mathrm{N}$ & $\mathrm{N}$ & $\mathrm{N}$ \\
\hline Cohort dummy & $\mathrm{Y}$ & $\mathrm{Y}$ & $\mathrm{Y}$ & $\mathrm{Y}$ & $\mathrm{Y}$ & $\mathrm{Y}$ \\
\hline $\mathrm{N}$ & 892,225 & 778,491 & 626,761 & 315,590 & 723,055 & 453,822 \\
\hline
\end{tabular}

Notes: All regressions are clustered at the student level and include cutoff fixed effects. Standard errors are in parentheses. All panels present reduced form specifications where the key independent variable is a dummy for the interaction of the unwanted dummy and the dummy for whether a student's transition score is greater than or equal to the cutoff. The dependent variables are defined in Table 1.

$* p<0.10, * * p<0.05, * * * p<0.01$ 
TABLE 12. Interactions controlling for mothers' education (survey respondents)

\begin{tabular}{|c|c|c|c|c|c|c|}
\hline & \multicolumn{2}{|c|}{ Bacc. taken } & \multicolumn{2}{|c|}{ Bacc. grade } & \multicolumn{2}{|c|}{ Romanian Bacc. grade } \\
\hline & $\begin{array}{c}\text { Within } \\
1 \text { point } \\
\text { of cutoff } \\
\text { (1) }\end{array}$ & $\begin{array}{l}\text { Within } \\
\text { IK } \\
\text { bound } \\
(2)\end{array}$ & $\begin{array}{c}\text { Within } \\
1 \text { point } \\
\text { of cutoff } \\
\text { (3) }\end{array}$ & $\begin{array}{l}\text { Within } \\
\text { IK } \\
\text { bound } \\
(4)\end{array}$ & $\begin{array}{c}\text { Within } \\
1 \text { point } \\
\text { of cutoff } \\
(5)\end{array}$ & $\begin{array}{l}\text { Within } \\
\text { IK } \\
\text { bound } \\
(6)\end{array}$ \\
\hline \multicolumn{7}{|l|}{ Panel A } \\
\hline Access to a better school (Access $B)$ & $\begin{array}{c}0.019 \\
{[0.066]}\end{array}$ & $\begin{array}{c}0.019 \\
{[0.063]}\end{array}$ & $\begin{array}{c}0.012 \\
{[0.204]}\end{array}$ & $\begin{array}{c}0.039 \\
{[0.171]}\end{array}$ & $\begin{array}{c}-0.046 \\
{[0.219]}\end{array}$ & $\begin{array}{c}-0.062 \\
{[0.177]}\end{array}$ \\
\hline Abortion access (AccessA) & $\begin{array}{c}-0.060 \\
{[0.050]}\end{array}$ & $\begin{array}{c}-0.030 \\
{[0.046]}\end{array}$ & $\begin{array}{c}0.212 \\
{[0.154]}\end{array}$ & $\begin{array}{c}0.147 \\
{[0.141]}\end{array}$ & $\begin{array}{c}0.287^{*} \\
{[0.156]}\end{array}$ & $\begin{array}{c}0.179 \\
{[0.139]}\end{array}$ \\
\hline Access $B * A c c e s s A$ & $\begin{array}{c}0.021 \\
{[0.062]}\end{array}$ & $\begin{array}{c}-0.007 \\
{[0.056]}\end{array}$ & $\begin{array}{c}-0.155 \\
{[0.193]}\end{array}$ & $\begin{array}{c}-0.112 \\
{[0.161]}\end{array}$ & $\begin{array}{l}-0.336 * \\
{[0.203]}\end{array}$ & $\begin{array}{c}-0.237 \\
{[0.164]}\end{array}$ \\
\hline Monthly trend & $\mathrm{Y}$ & $\mathrm{Y}$ & $\mathrm{Y}$ & $\mathrm{Y}$ & $\mathrm{Y}$ & $\mathrm{Y}$ \\
\hline Calendar month dummies & $\mathrm{N}$ & $\mathrm{N}$ & $\mathrm{N}$ & $\mathrm{N}$ & $\mathrm{N}$ & $\mathrm{N}$ \\
\hline Cohort dummy & $\mathrm{Y}$ & $\mathrm{Y}$ & $\mathrm{Y}$ & $\mathrm{Y}$ & $\mathrm{Y}$ & $\mathrm{Y}$ \\
\hline $\mathrm{N}$ & 3,558 & 4,244 & 3,012 & 5,309 & 3,303 & 5,445 \\
\hline \multicolumn{7}{|l|}{ Panel B } \\
\hline Access to a better school (AccessB) & $\begin{array}{c}-0.007 \\
{[0.025]}\end{array}$ & $\begin{array}{c}0.008 \\
{[0.023]}\end{array}$ & $\begin{array}{c}0.077 \\
{[0.104]}\end{array}$ & $\begin{array}{c}0.102 \\
{[0.085]}\end{array}$ & $\begin{array}{c}0.055 \\
{[0.102]}\end{array}$ & $\begin{array}{c}0.129 \\
{[0.082]}\end{array}$ \\
\hline Educated Mother dummy & $\begin{array}{l}-0.022 \\
{[0.031]}\end{array}$ & $\begin{array}{l}-0.012 \\
{[0.028]}\end{array}$ & $\begin{array}{c}0.228 * \\
{[0.119]}\end{array}$ & $\begin{array}{l}0.220 * * \\
{[0.106]}\end{array}$ & $\begin{array}{c}0.108 \\
{[0.120]}\end{array}$ & $\begin{array}{c}0.145 \\
{[0.103]}\end{array}$ \\
\hline Access $B^{*}$ Educated Mother & $\begin{array}{c}0.030 \\
{[0.037]}\end{array}$ & $\begin{array}{c}0.020 \\
{[0.034]}\end{array}$ & $\begin{array}{l}-0.017 \\
{[0.149]}\end{array}$ & $\begin{array}{c}0.020 \\
{[0.121]}\end{array}$ & $\begin{array}{c}-0.004 \\
{[0.150]}\end{array}$ & $\begin{array}{c}-0.046 \\
{[0.120]}\end{array}$ \\
\hline Monthly trend & $\mathrm{Y}$ & $\mathrm{Y}$ & $\mathrm{Y}$ & $\mathrm{Y}$ & $\mathrm{Y}$ & $\mathrm{Y}$ \\
\hline Calendar month dummies & $\mathrm{N}$ & $\mathrm{N}$ & $\mathrm{N}$ & $\mathrm{N}$ & $\mathrm{N}$ & $\mathrm{N}$ \\
\hline Cohort dummy & $\mathrm{Y}$ & $\mathrm{Y}$ & $\mathrm{Y}$ & $\mathrm{Y}$ & $\mathrm{Y}$ & $\mathrm{Y}$ \\
\hline $\mathrm{N}$ & 3,251 & 3,888 & 2,775 & 4,923 & 3,032 & 5,032 \\
\hline Panel C & & & & & & \\
\hline Access to a better school (AccessB) & $\begin{array}{c}0.024 \\
{[0.066]}\end{array}$ & $\begin{array}{c}0.027 \\
{[0.062]}\end{array}$ & $\begin{array}{l}-0.018 \\
{[0.215]}\end{array}$ & $\begin{array}{c}0.017 \\
{[0.181]}\end{array}$ & $\begin{array}{c}-0.102 \\
{[0.235]}\end{array}$ & $\begin{array}{c}-0.088 \\
{[0.188]}\end{array}$ \\
\hline Abortion access (Access $A)$ & $\begin{array}{c}-0.053 \\
{[0.051]}\end{array}$ & $\begin{array}{c}-0.028 \\
{[0.047]}\end{array}$ & $\begin{array}{c}0.156 \\
{[0.163]}\end{array}$ & $\begin{array}{c}0.147 \\
{[0.150]}\end{array}$ & $\begin{array}{c}0.157 \\
{[0.166]}\end{array}$ & $\begin{array}{c}0.089 \\
{[0.148]}\end{array}$ \\
\hline Access $B^{*}$ Access $A$ & $\begin{array}{l}-0.005 \\
{[0.064]}\end{array}$ & $\begin{array}{c}-0.024 \\
{[0.058]}\end{array}$ & $\begin{array}{l}-0.079 \\
{[0.202]}\end{array}$ & $\begin{array}{l}-0.093 \\
{[0.169]}\end{array}$ & $\begin{array}{l}-0.240 \\
{[0.215]}\end{array}$ & $\begin{array}{c}-0.170 \\
{[0.173]}\end{array}$ \\
\hline Educated Mother dummy & $\begin{array}{c}0.008 \\
{[0.017]}\end{array}$ & $\begin{array}{c}0.009 \\
{[0.017]}\end{array}$ & $\begin{array}{c}0.096 * \\
{[0.053]}\end{array}$ & $\begin{array}{l}0.091 * \\
{[0.053]}\end{array}$ & $\begin{array}{l}-0.006 \\
{[0.055]}\end{array}$ & $\begin{array}{c}0.000 \\
{[0.053]}\end{array}$ \\
\hline Access $B^{*}$ Educated Mother & $\begin{array}{c}-0.014 \\
{[0.020]}\end{array}$ & $\begin{array}{c}-0.013 \\
{[0.019]}\end{array}$ & $\begin{array}{c}-0.089 \\
{[0.062]}\end{array}$ & $\begin{array}{c}-0.075 \\
{[0.057]}\end{array}$ & $\begin{array}{c}-0.050 \\
{[0.065]}\end{array}$ & $\begin{array}{c}-0.063 \\
{[0.059]}\end{array}$ \\
\hline Monthly trend & $\mathrm{Y}$ & $\mathrm{Y}$ & $\mathrm{Y}$ & $\mathrm{Y}$ & $\mathrm{Y}$ & $\mathrm{Y}$ \\
\hline Calendar month dummies & $\mathrm{N}$ & $\mathrm{N}$ & $\mathrm{N}$ & $\mathrm{N}$ & $\mathrm{N}$ & $\mathrm{N}$ \\
\hline Cohort dummy & $\mathrm{Y}$ & $\mathrm{Y}$ & $\mathrm{Y}$ & $\mathrm{Y}$ & $\mathrm{Y}$ & $\mathrm{Y}$ \\
\hline $\mathrm{N}$ & 3,251 & 3,888 & 2,775 & 4,923 & 3,032 & 5,032 \\
\hline
\end{tabular}

Notes: All regressions are clustered at the student level and include cutoff fixed effects. Standard errors are in parentheses. All panels present reduced form specifications where the key independent variable is a dummy for the interaction of the unwanted dummy and the dummy for whether a student's transition score is greater than or equal to the cutoff. The dependent variables are defined in Table 1.

$* p<0.10,{ }^{* *} p<0.05,{ }^{* * *} p<0.01$ 